أثر برنامج للتمرينات الرياضية العلاجية لتخفيف آلام أسفل الظهر وآلام الركبتين لاى آلامهات الحوامل لرياته

\author{
منيب عبدالله فتحي
}

جامعة الموصل / كلية التربية الرياضية

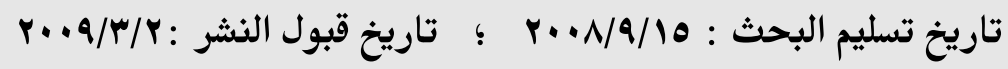

\title{
الملخص
}

هدفت الدراسة الى اعداد برنامج للتمارين الرياضية العلاجية لتخفيف آلام اسفل الظهر التهر

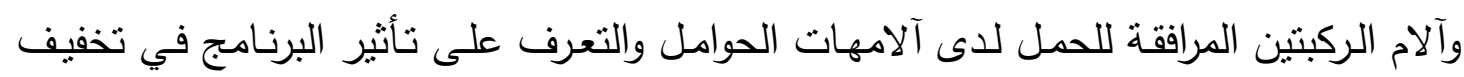
الالم وكذلك التعرف على اي من المنطقتين اسفل الظهر ام الركبتين نأثيره بشكل أفضل.

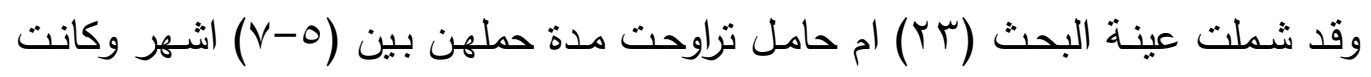

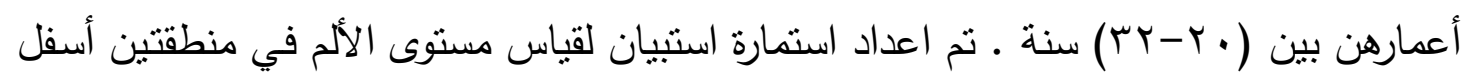

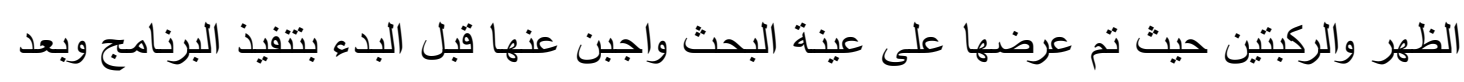

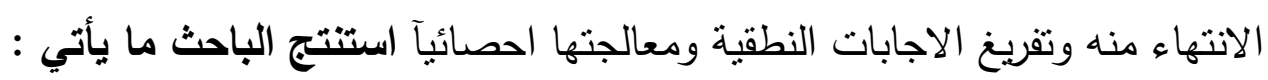

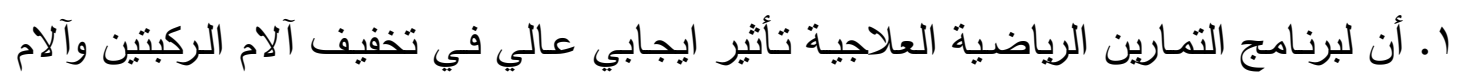

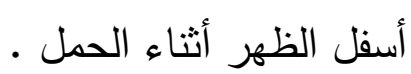
r. أفادة الدراسة أن للتمارين الرياضية الموجهة لإغراض علاجية تأثير ايجابي في تخفيف آلام

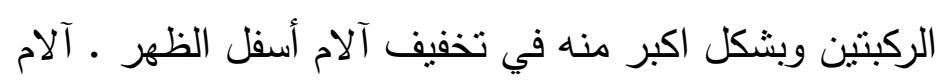
وقد أوصى الباحث بما يأتي :

1. تعميم برنامج التمارين الرياضية العلاجية على المراكز الطبية التي تعنى بصحة آلام الحامل

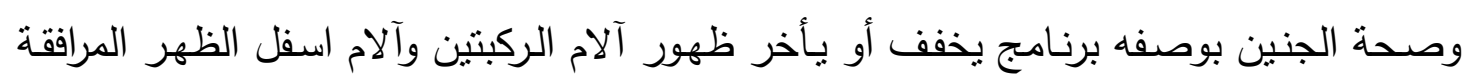
للحمل. r. العناية بالتمارين الرياضية الموجهة خلال فترة الحمل لضمان حمل صحي خالي من المشاكل

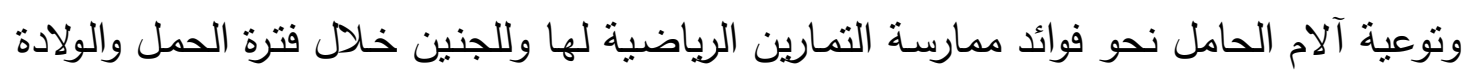
وبعدها. r. التقليل من استخدام الأدويـة المسكنة لهـا لها مـن تأثثر جـانبي على صحة آلام والجنين والاهتمام بالعلاج الطبيعي كبديل مفيد وآمن . 


$$
\begin{aligned}
& \text { ع. تتظيم نـدوات علميـة مشتركة بين المختصين بالطب الرياضـي والعـلاج الطبيعي لتقريب } \\
& \text { وجهات النظر العلمية لما فيه مصلحة آلام الحامل والجنين . }
\end{aligned}
$$

\section{ABSTRACT \\ Effects of Athletic and Therapeutic Exercises Program to Decrease on the Lower Back Pain and Knee Joint Pain in pregnant Women}

\section{Muneeb A Fathi}

\section{Mosul university / college of physical education}

The study aimed at setting athletic and therapeutic exercises program to decrease the lower back pain and knee joint associating pregnancy and acquainting the effects of the two areas is affected more . program to reduce the pain in addition to know which .

The sample included (23) pregnant women. their averaged (20-32) years. and their pregnancy durations were between (5-7) months. The researcher sets a questionnaire to assess the pain of lower back as well as the grade of pain. After that. the questionnaire was presented to the sample to answer it pre and post carrying out the program. After collecting the data and processing it statistically. the following results were found:

1. The study found that the presented program helps in relieving both lower back pain as well as knee joint pain in pregnant women.

2. It was also found that the program was more helpful in relieving knee joint pain than lower back pain.

The study recommended the following:

1. Generalization of the program to medical centers that are concerned with pregnant women and maternal health.

2. Encouraging pregnant women to practice specific exercises during and after pregnant that are useful. safe. and easy to perform to insure healthy pregnancy.

3. Avoid using analgesic because they have side effects.

4. Arranging scientific meetings among experts of pregnancy. sport medicine and physiotherapy to encourage these people to advice pregnant women to make use of this program and similar programs. 
1- 1 المقدمة وأهمية البحث

مما لا شك فيه أن الحمل والولادة سر عظيم من اسرار الخالق عز وجل فلو تأملنا مراحل تكوين الخلق البشري منذ تكوينه الجنيني ونموه في احثاء امه بكامل اعضائه وصفاته الهاء المتوارثنة

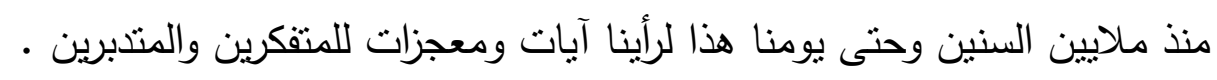
وآلام هي الأرض الخصبة التي فيها يغرس ويترعرع ذلك المخلوق ليصبح طفلا متكاملا، وتحتاج آلام الحامل لعوامل كثثرة لتنعم بحمل صحي من تللك العوامل التغذية المتكاملة والمتوازنة

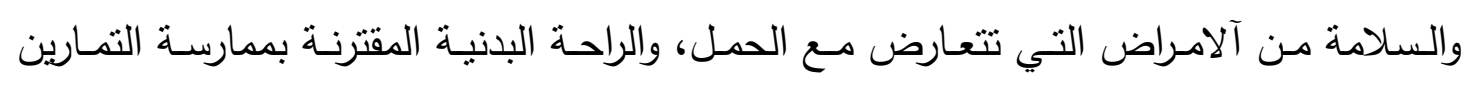

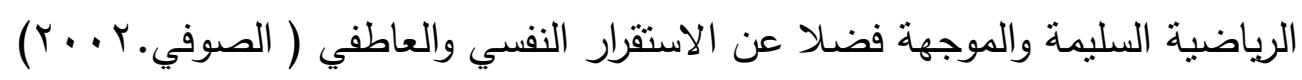

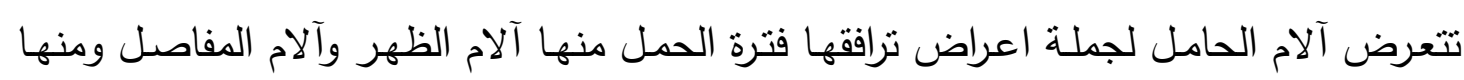

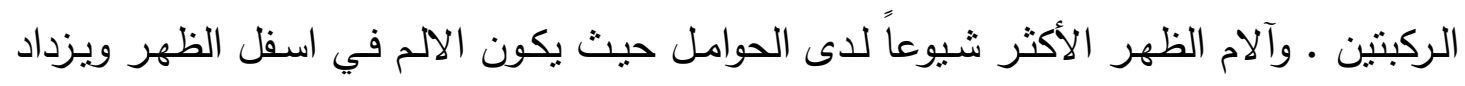

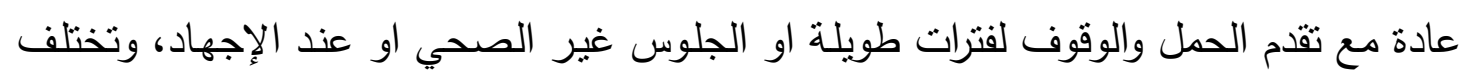

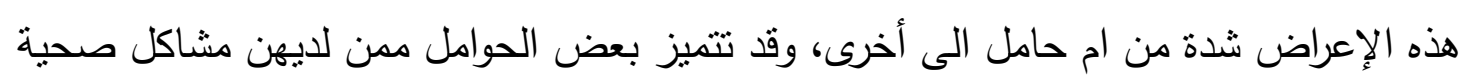

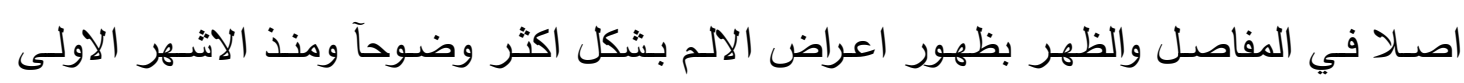
للحمل.

وتتركز أهمية البحث بأعداد برنامج علاجي يتضمن تمرينات رياضية موجهة لعلاج آلام أسفل الظهر وآلام الركبتين للمساهمة في تخفيف وتقليل المشاكل الصحية التي نواجهة آلامهات

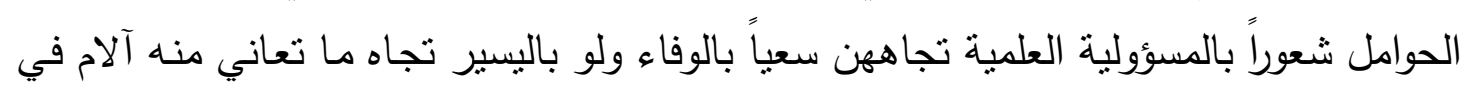

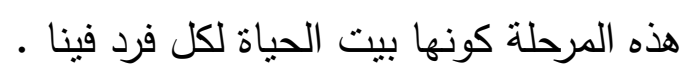

\section{r- r مشكلة البحث}

نظراً للتغييرات الفسيولوجية والمورفولوجية التي تتعرض لها المرأة الحامل وما تسببه من

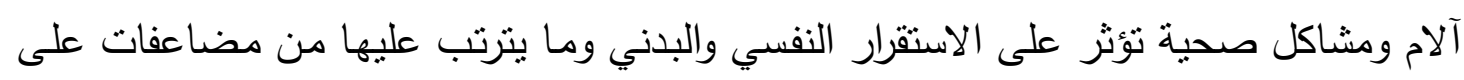

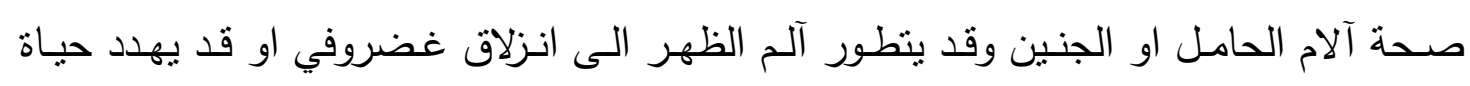

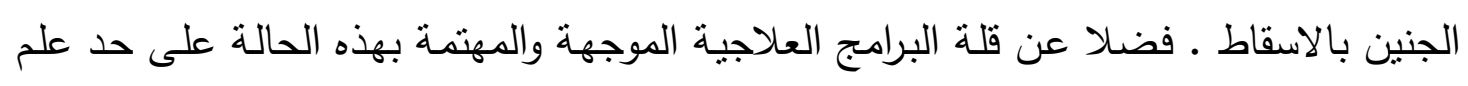
الباحث ـ لذا أرتى الباحث اعداد برنامج علاجي لتخفيف وعلاج آلام اسفل الظهر وآلام الركبتين

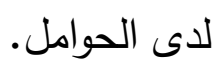


1-r-1 أعداد برنامج علاجي لتخفيف آلام أسفل الظهر وآلام الركبتين لدى آلامهات الحوامل.

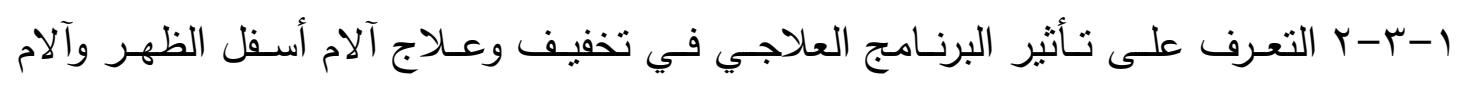

$$
\text { الركبتين لدى لأمهات الحوامل. }
$$

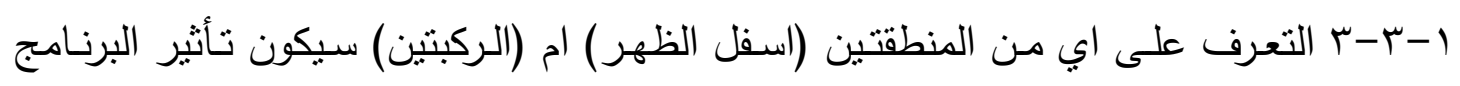
بشكل أكبر .

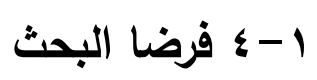

1-ع - 1 هنالك تأثثر ايجابي للبرنامج العلاجي في تخفيف آلام اسفل الظهر وآلام الركبنتن لدى

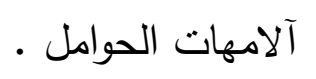

1-؟-r هنالك تأثير ايجابي للبرنامج وبشكل أكبر على احدى منطقتي آلام أسفل الظهر ام

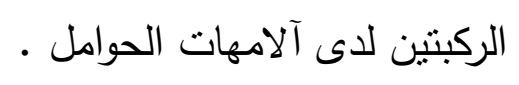

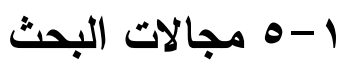

1-0 - المجال البشري : آلامهات الحوامل المراجعات لمركز صحة المرأة الحامل التابع لمستشفى الخنساء التعليمي وبعض العيادات الخاصـة لمعالجـة المهات

$$
\text { النساء. }
$$

1- ا المجال المكاني : مركز صحة المرأة في مستثفى الخنساء التعليمي وبعض العيادات

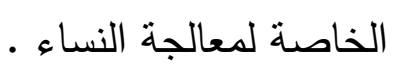

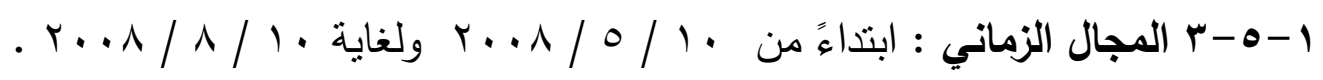

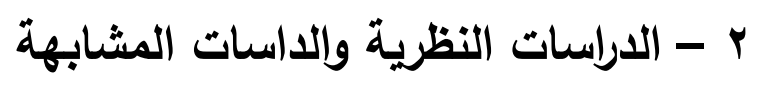
r r r r r r r r الداسات النظرية

\section{ץ- - - ا الحمل والمشاكل الصحية المرافق له}

تتميز الأشـهر الأخيرة من الحمل بالكثير من المشاكل للنساء الحوامل ولاسيما لمن كان الهان

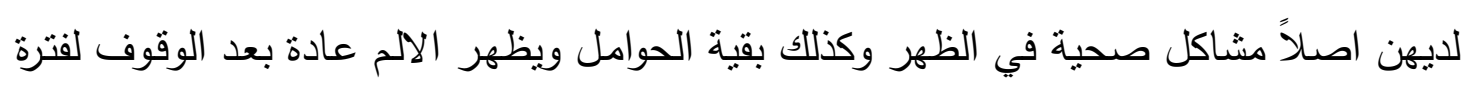

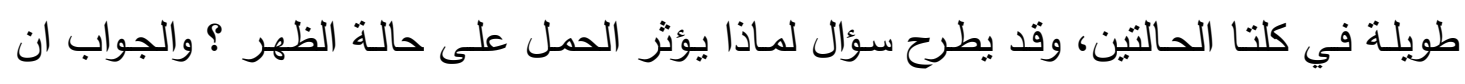
السبب الرئيس لألم الظهر هو افراز الجسم عند الاستعداد للولادة هرمون يحمل اسم (ريلاكسين)

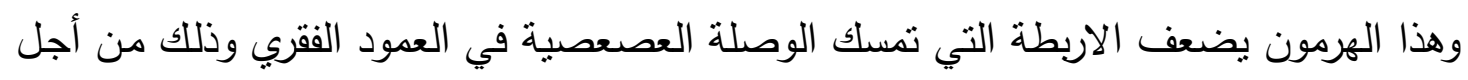

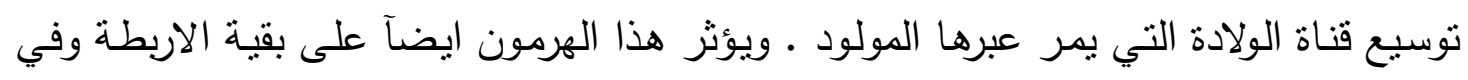

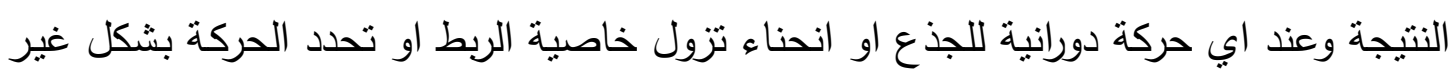

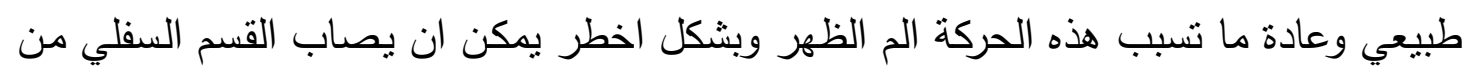

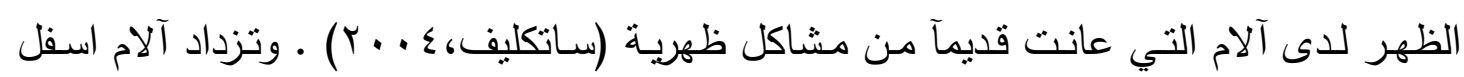




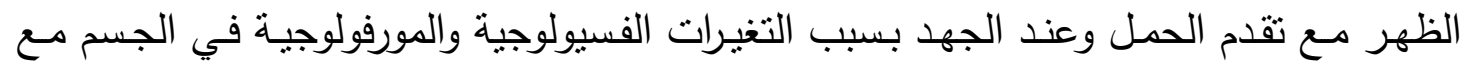
ازدياد وزن آلام الحامل ـ كما قد تتعرض الحامل للانزلاق الغضروفي للفقرات القطنية اذ تمتند

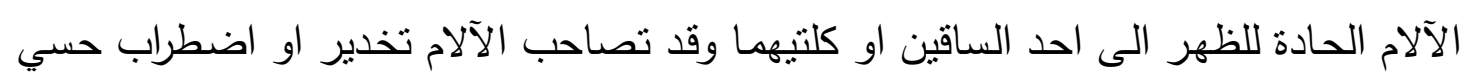

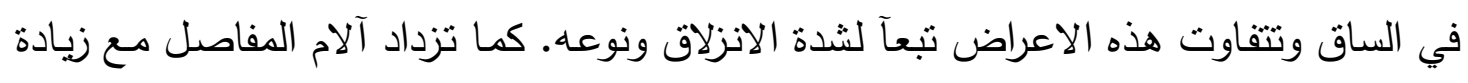

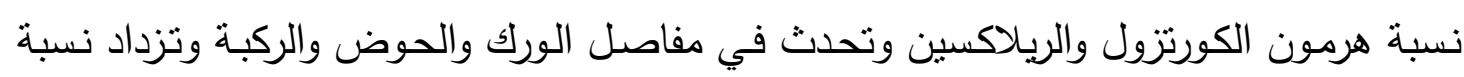

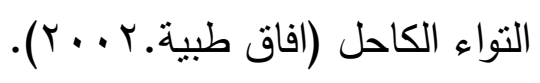

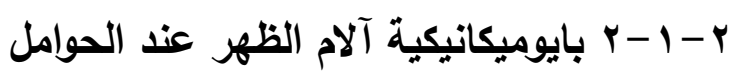

ان تأثثر هرموني ريلاكسين والكرتزول على الأربطة ليس هو التانئير الوحيد الذي يؤثن

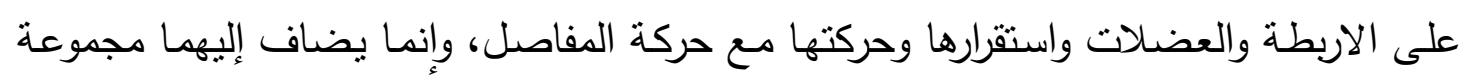

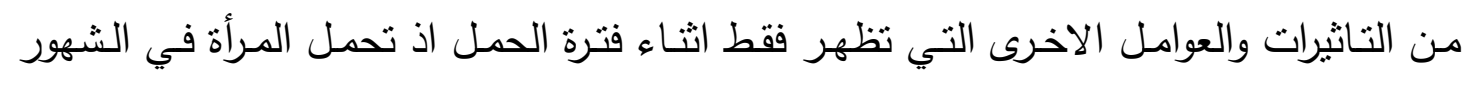

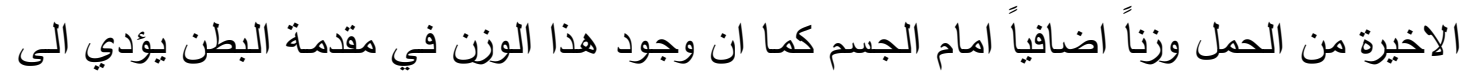

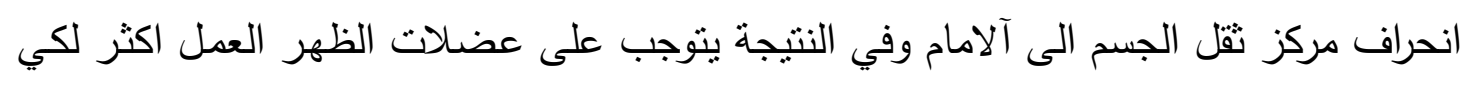

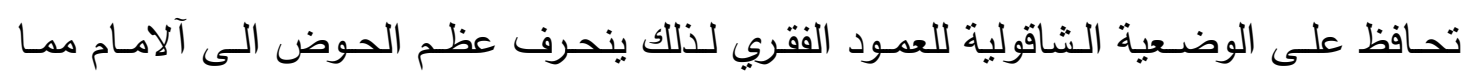
يضاعف من انحناء الجزء القطني من العمود الفقري فينحرف مركز التقل لدى الحامل عن مساره الطبيعي فتظهر آلام أسفل الظهر وهذا بدوره يؤدي الى تخلخل الصف المنتظم للفقرات فيزداد

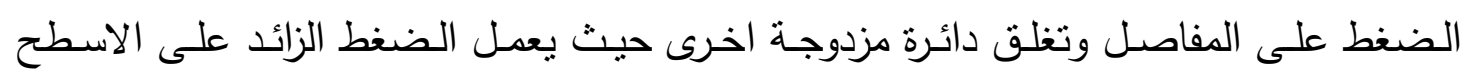

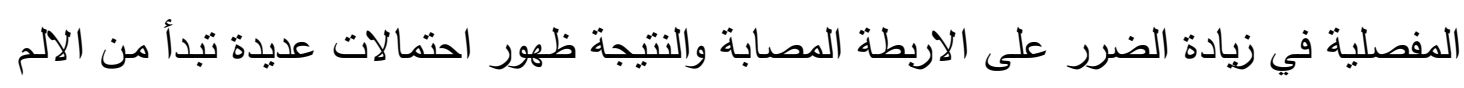
المستمر وتتنهي بالالتهاب ومتلازمة العصب الوركي وما يسمى بعرق النساء ، لذادا لا ينصح

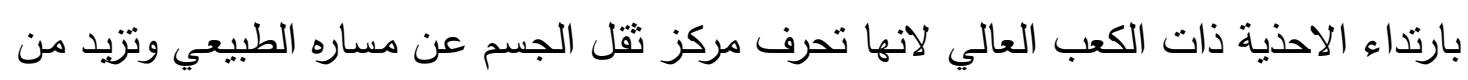

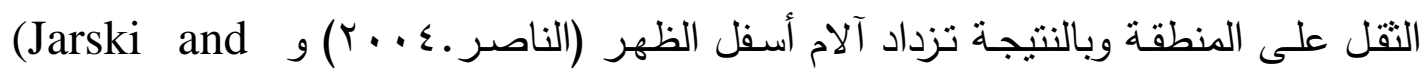

.Trippett.1990)

r-1 - ب أهمية التمارين الرياضية للحامل

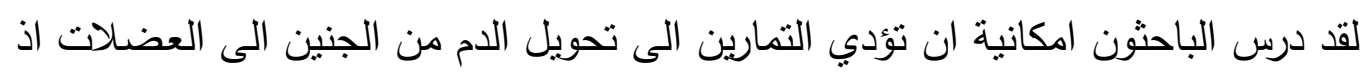

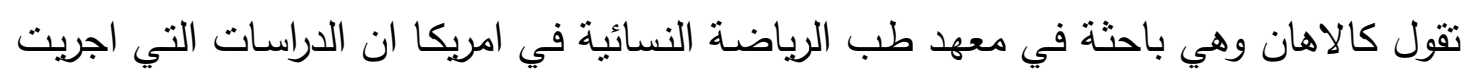

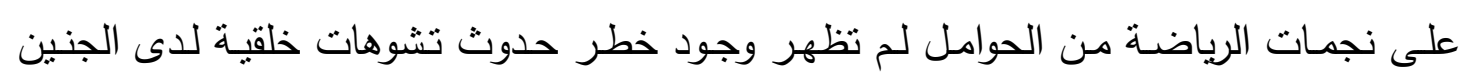

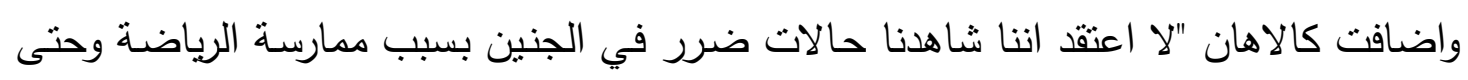

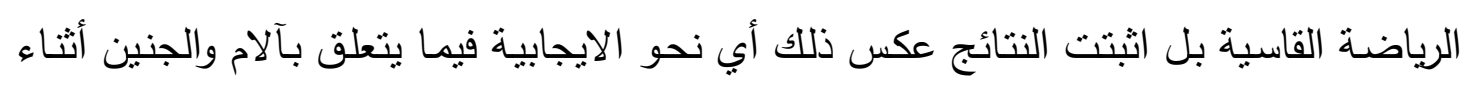

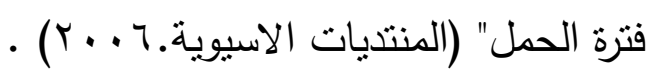


ترافق آلام الحامل منذ الاثـهر الاولى آلام الظهر بسبب ارتخـاء المفاصل الناتج عن

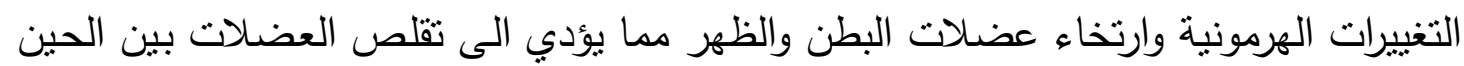
والاخر ويظهر الم الظهر للذا بتعلم الوضـع الافضل لتخفيف الالم وتعلم الوضـع الفيزيـائي والميكانيكي للجسم اي كيف تجلس وكيف تحمل الاشياء واستخدام الحزام الفقري واداء التمارين الرياضية الخاصة والموجهة على الظهر والفخذين والرجلين (طبيب. ج . . ب).

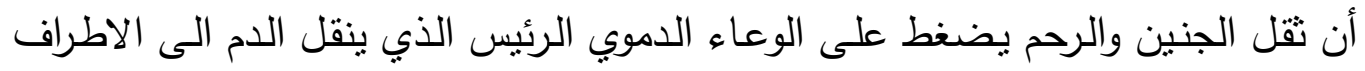

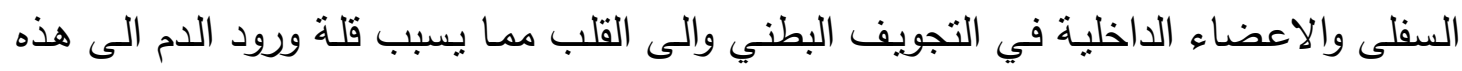

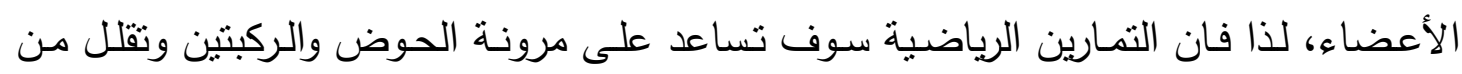

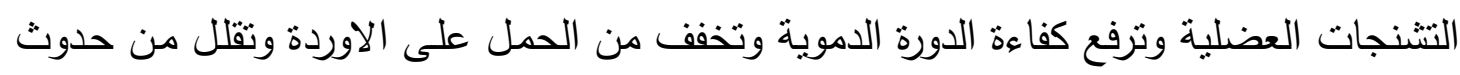

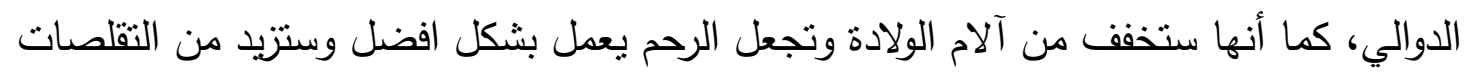

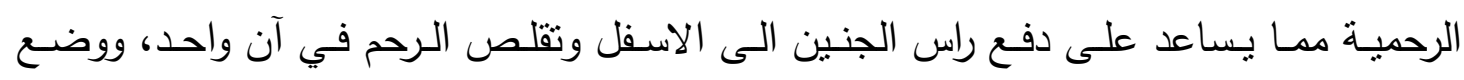

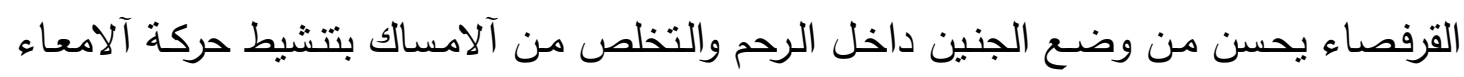

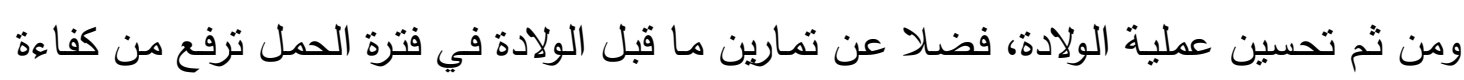
العضلات وتمنح آلام الحامل فوائد عديدة اهمها:

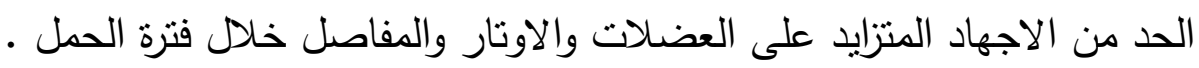

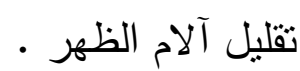

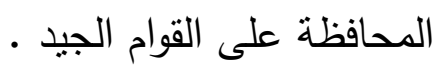
رفع كفاءة عضلات البطن والحوض وتقويتها لانها تدعم تضخم الرحم مع كبر حجم الجنين،

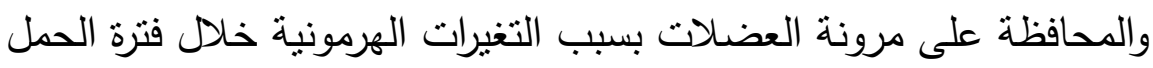
ت تقليل الاحساس بالتقل على الحوض.

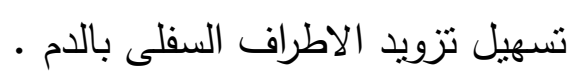
تقليل ضغوط الحياة اليومية والثعور بالنشاط .

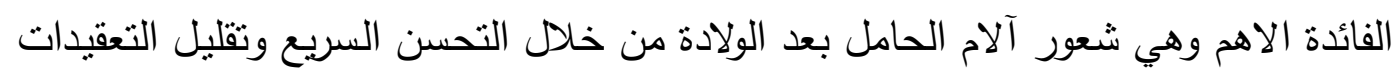

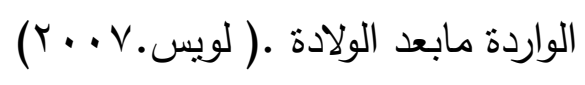

r- - - - آلام الظهر وإلمفاصل أسبابها وعلاجها تعد آلام الظهر من المعوقات الرئيسة لنشاط الفرد حيث ان ملازمة الم الظهر والمفاصل

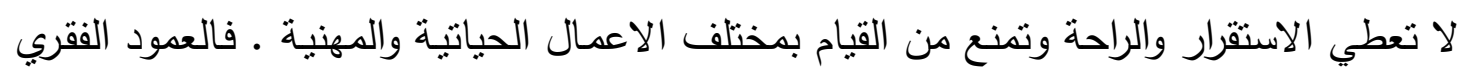

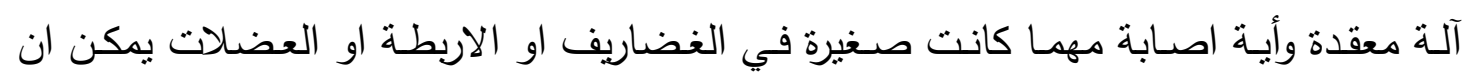

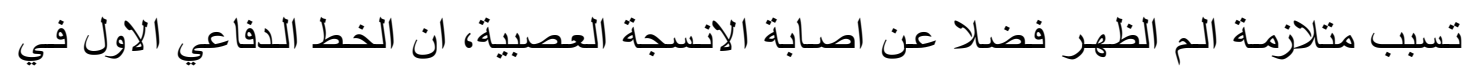
الجهاز الحركي الهيكلي لجسم الانسان هو العضلات حيث يؤدي عدم توازن القوى العضلية 
وضعف عضلات البطن الى الضغط على الفقرات فتتضغط وتقترب الواحدة من الاخرى وهذا ما

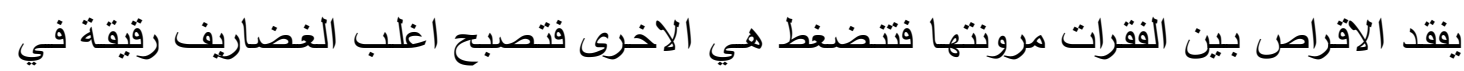
النتيجة وتتآكل اطراف الفقرات او يبرز عليها زوائد غضروفية ويعد الخلل في وظيفة العضلات

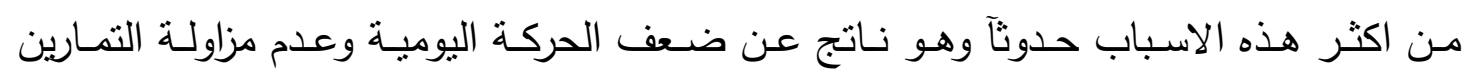

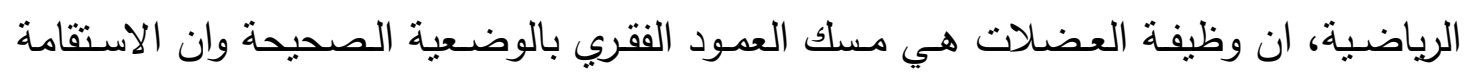

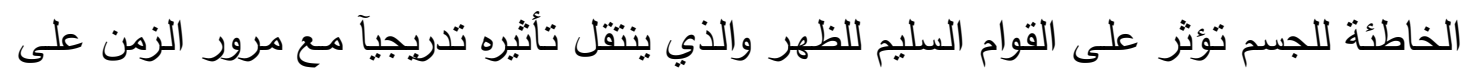

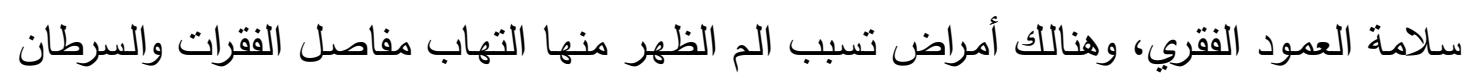
والقصور الكلوي وآلامراض النسائية نسبب الم اسفل الظهر وتلين العظام وترقق العظام والانزلاق

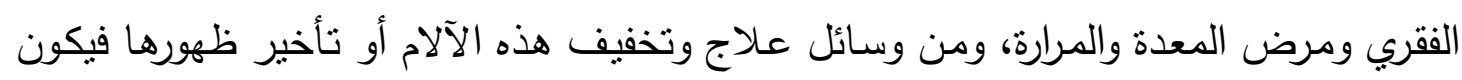

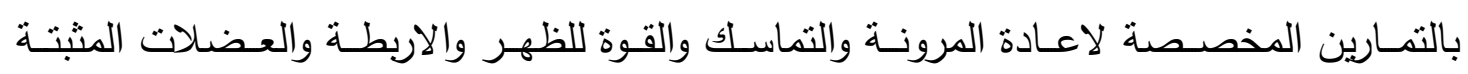

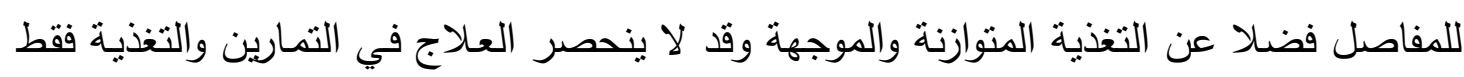

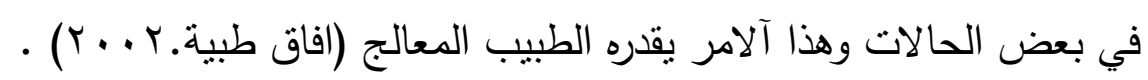

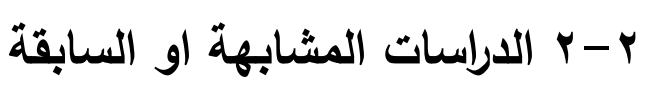

\section{: HALL AND KAUFMANN 1987 r-r 198}

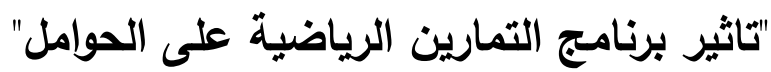

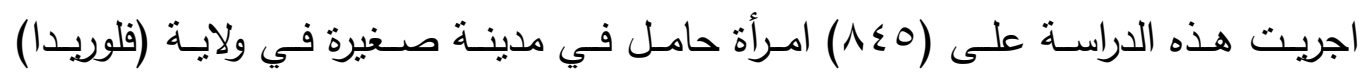

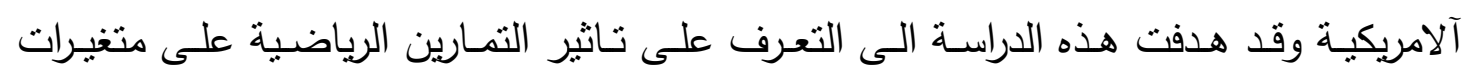
فسلجية ووظيفية هي ( نبض القلب عند الراحة، ضغط الدم عند الراحة، سمك الطبقة الثحمية

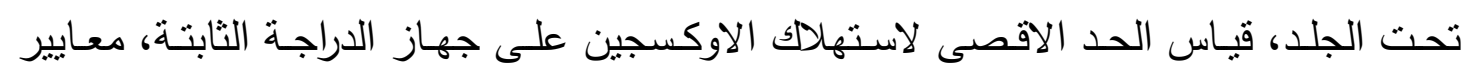

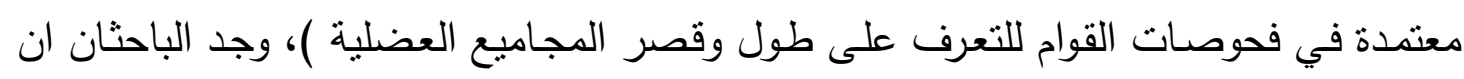

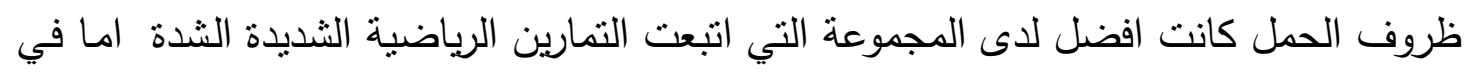

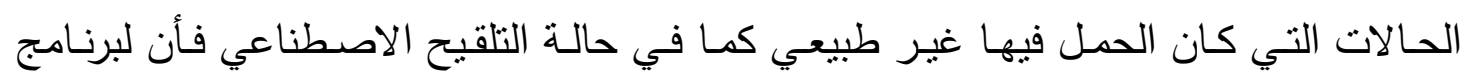

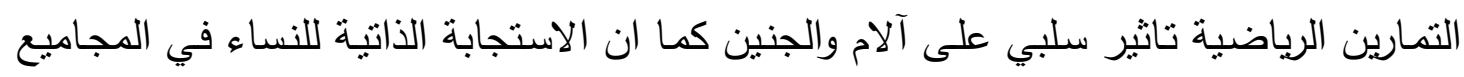

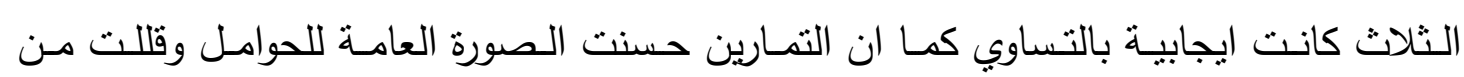

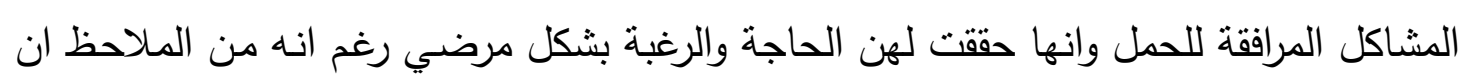

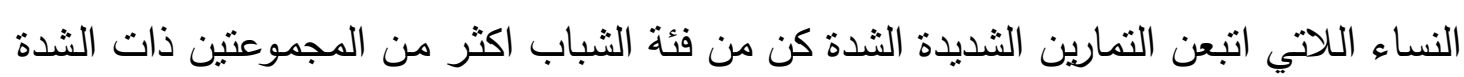
الخفيفة والمتوسطة (BIMMER.1994)

: $199 \vee$ (WONG and MCKENZIE) "تاثير الجها البذني على بعض المتغيرات الفسلجية والبدنية لاى الحوامل" 
أجريت هذه الدراسة على مجموعة صغيرة من النساء الحوامل تم تقسيمهن الى مجموعتين

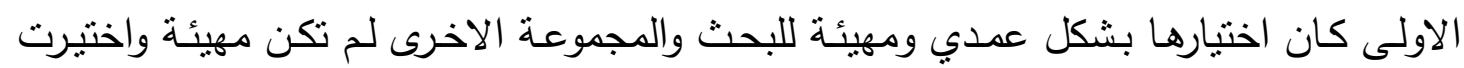

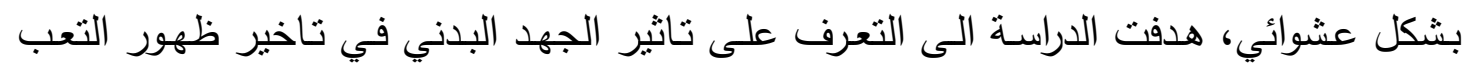

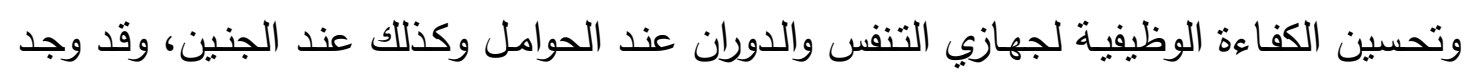

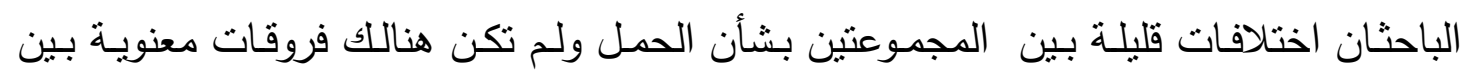

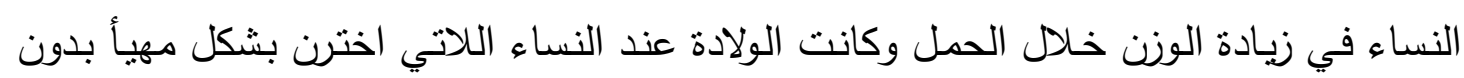

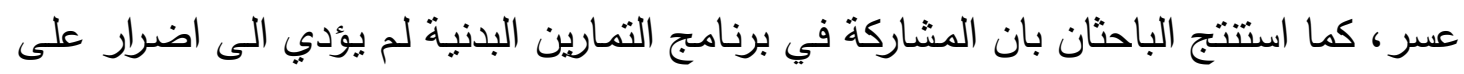

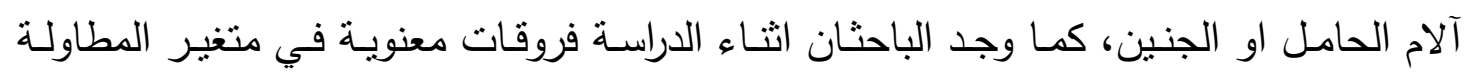

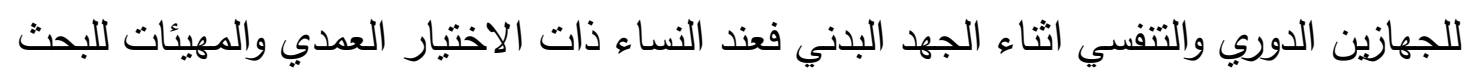

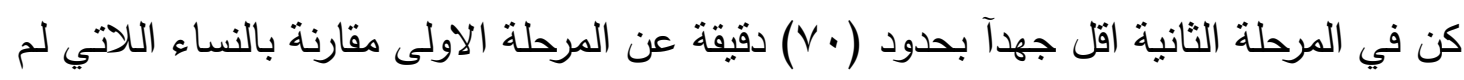

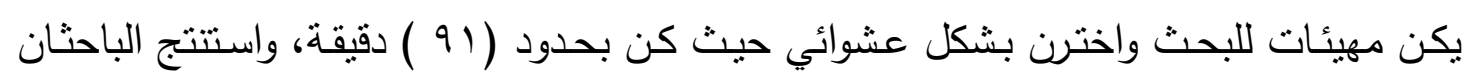
ايضا ان وقت الجهد القصير كان سببا في تحسين كفاءة الجهاز التتفسي والقدرة على مقاومة لإنة

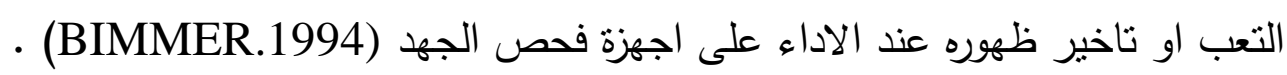

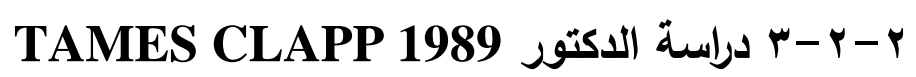
"تأثير الجها الهوائي الموجه على صحة الحامل والجنين"

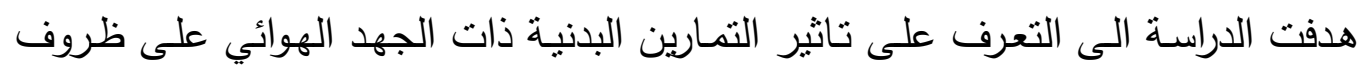

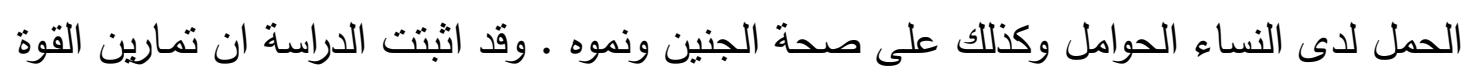

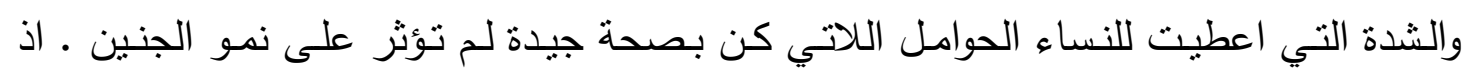

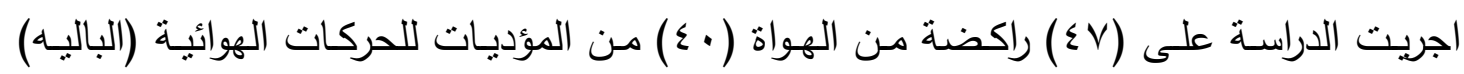

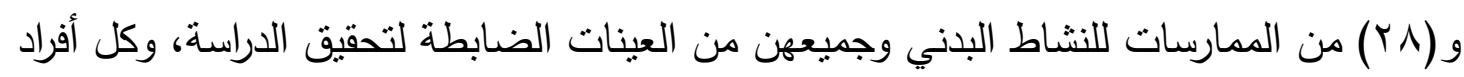

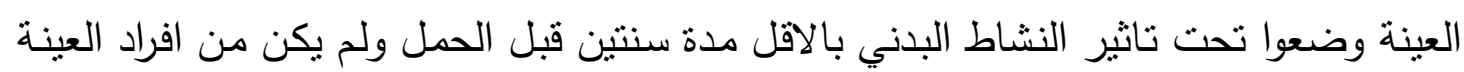

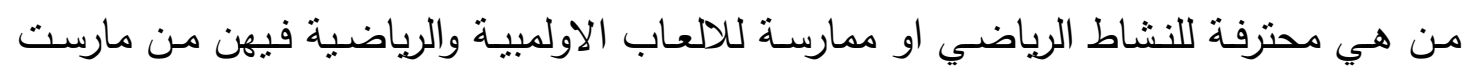

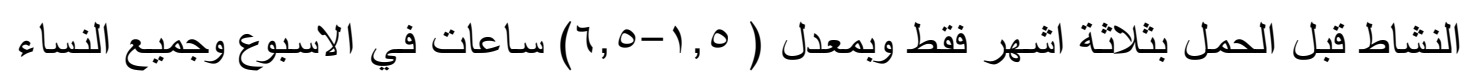

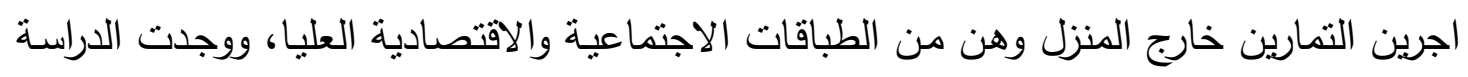

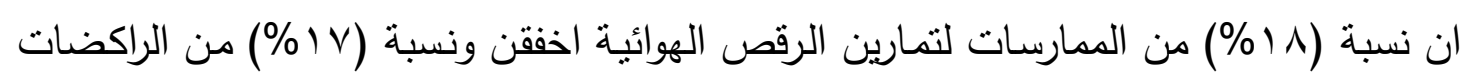

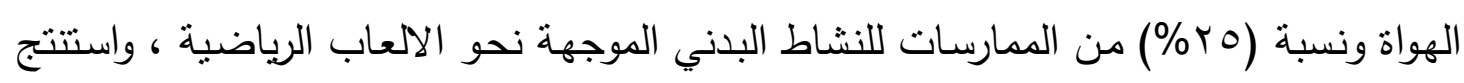

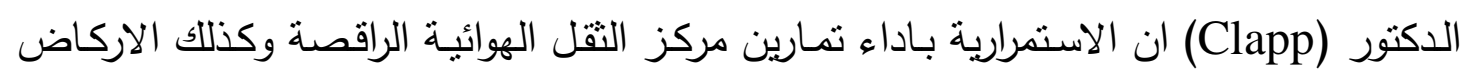

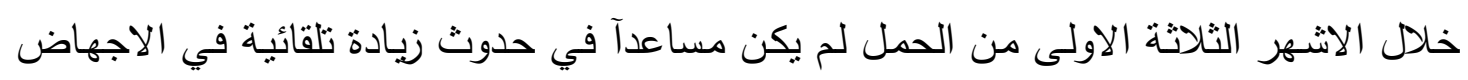

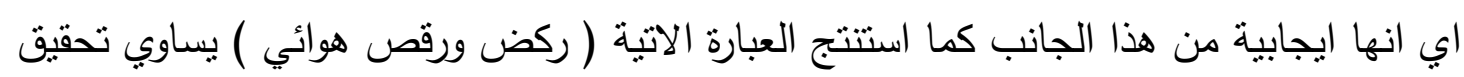


تطور معنوي في درجة حرارة الجسم وتطوير التجهيز الدموي وتحسين دورة اعادة الدم من الاوردة

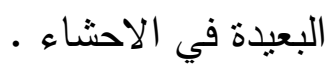

(Clapp.1989)

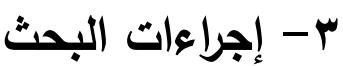

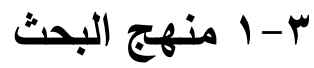

استخدم الباحث المنهج التجريبي لملائمته وطبيعة البحث .

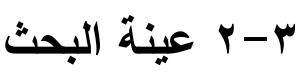

شـمل مجتمع البحث النساء الحوامل ممن لـيهن آلام اسفل الظهر والركبتين، وقد تم اختيار عينة البحث بالطريقة العدية من آلامهات الحوامل اللواتي يراجعن مستشفى (الخنساء)

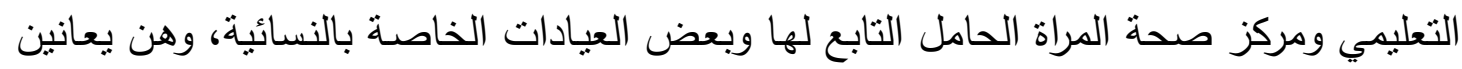

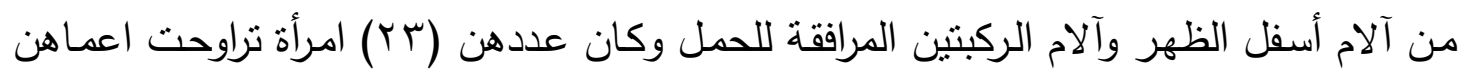

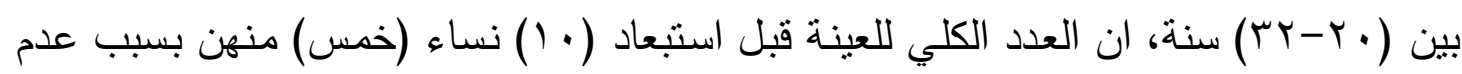
التزامهن بالبرنامج الى النهاية و (خمس) تم تجريب البرنامج عليهن للتعرف على امكانية اداء التمارين ومدى ملائمتها لعينة البحث. r-r r r r إجراءات البحث الميدانية

بعد اكتمال فكرة البحث قام الباحث باعداد برنامج التمارين البدنية معتمدآ على المصادر

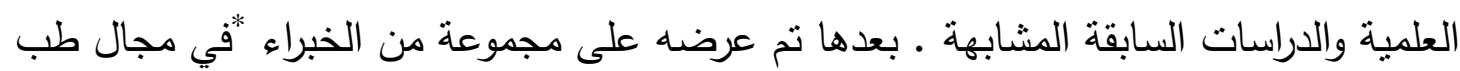

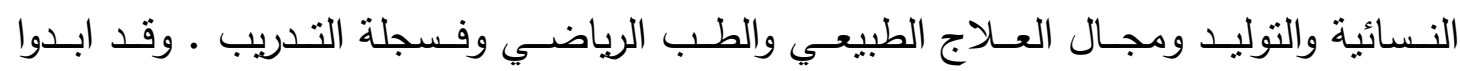
ملاحظاتهم وتعديلاتهم عليه ثم اعيدت صياغة وتتظيم البرنامج بعد الاخذ بملاحظات السادة

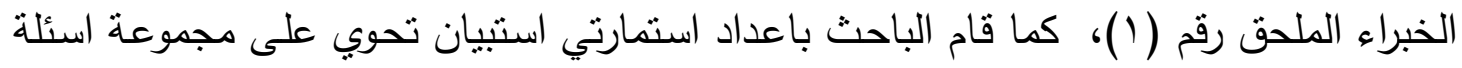

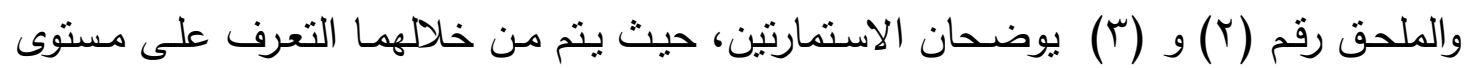

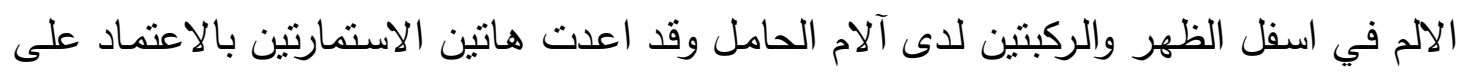

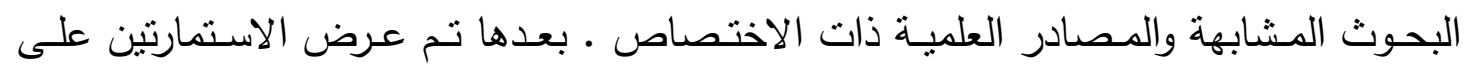
الخبراء نفسهم والمذكورين انفاً حيث قاموا بتقويم برنامج التمارين الرياضية وتتقيحه من النهات الناحية

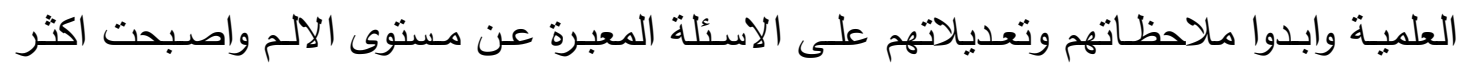
ملائمة لقياس مستوى الالم بعد ان وضعت بصيغتها النهائية ـ وبعد اتمام الاجراءات العلمية

$$
\begin{aligned}
& \text { * 1 أ.د. ياسين طه محمد علي ؟. أ.م.د عمار عبدالرحمن قبع }
\end{aligned}
$$

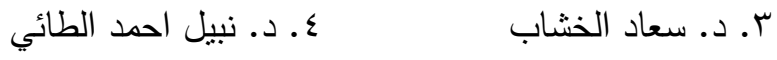


المتعلقة ببرنامج التمارين الرياضية واستمارتي استبيان الام قام الباحث بالتتسيق مـع الجهات التي من خلالها سيتم الاتصال بعينة البحث وترتيب المواعيد مع الطبيبات الاستشاريات بالنسائية

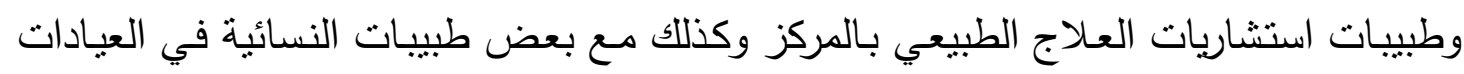

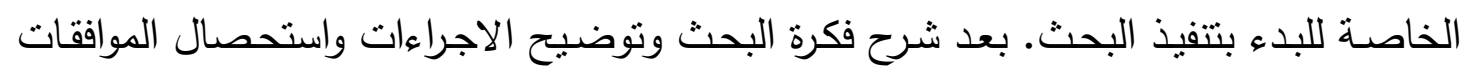

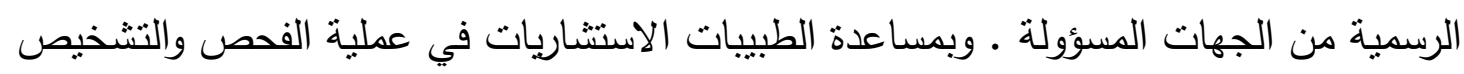
للحالة وتحويل النساء اللواتي بحاجة الى العلاج من آلام اسفل الظهر وآلام الركبتين المرافقة

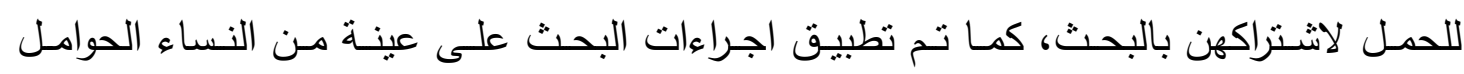

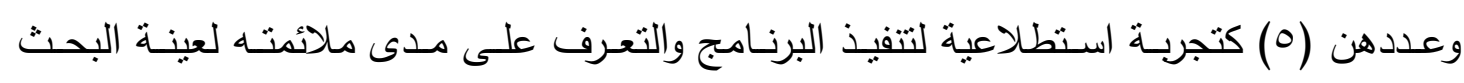

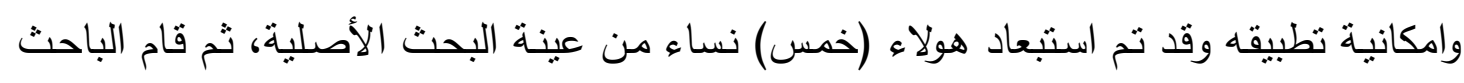

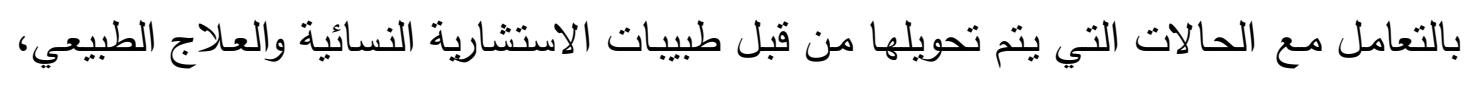

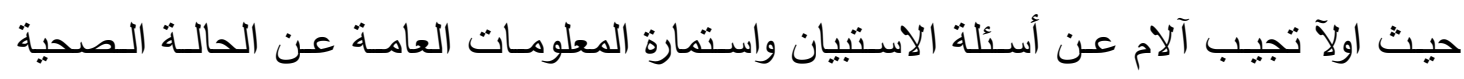

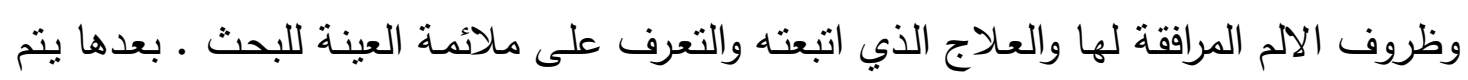
توضيح فكرة البحث لكل فرد من افراد العينة كي نتعرف على مدى استعدادهن للالتزام ورغبتهن

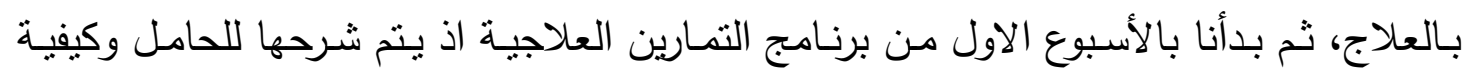

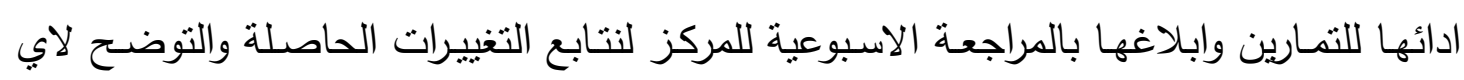
استفسار بخصوص التمارين وطريقة الاداء وهكذا استمر العمل طيلة فترة البحث وبعد استكمال

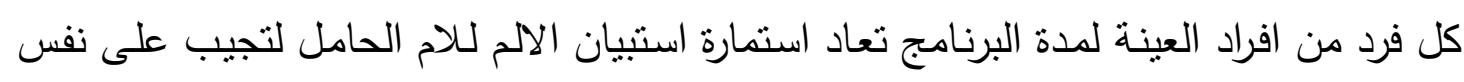

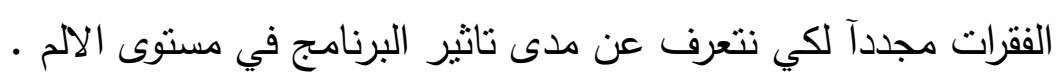

\section{r- ب برنامج التمارين الرياضية العلاجية}

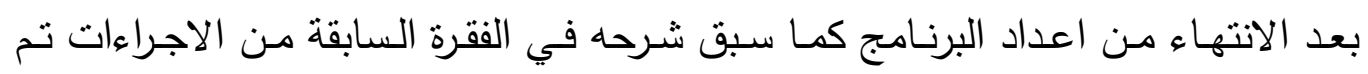

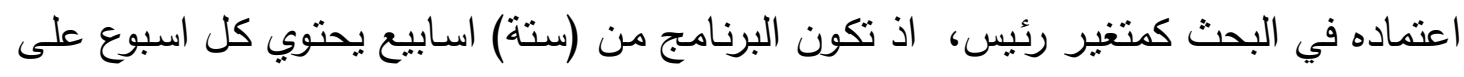

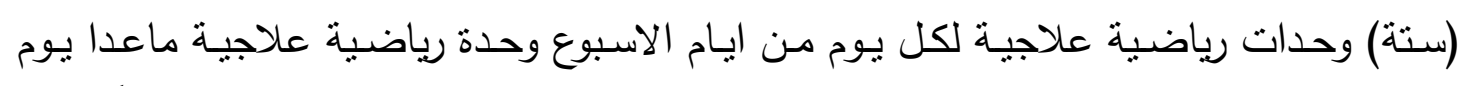

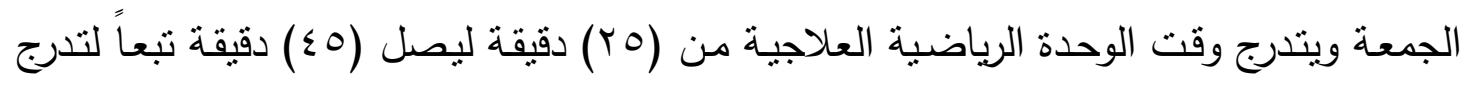

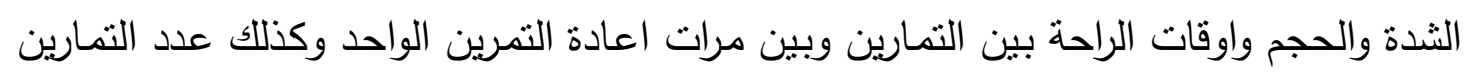

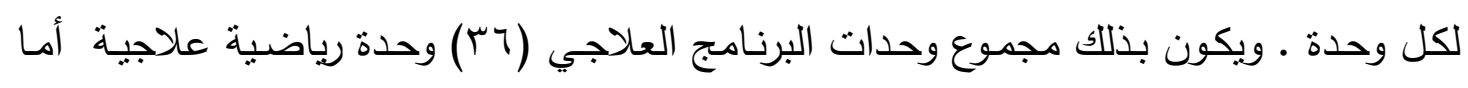
طبيعة التمارين التي يحتويها البرنامج فهي تمارين مرونة ثابتة ومرونة متحركة وتمارين قوة ثابتة

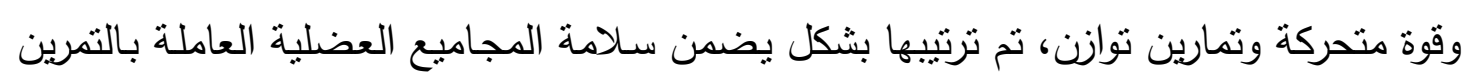

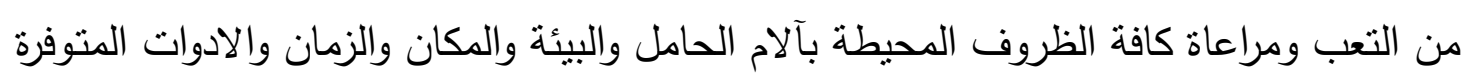

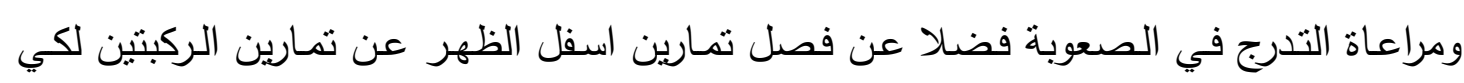

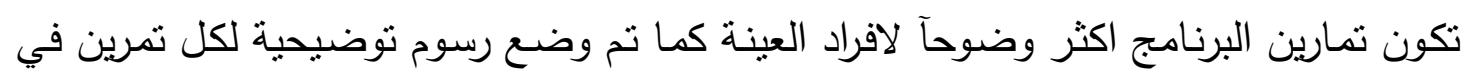


البرنامج لتسهيل فهم طريقة اداء التمرين، اذ تم تتفيذ التمارين من قبل عينة البحث في البيت

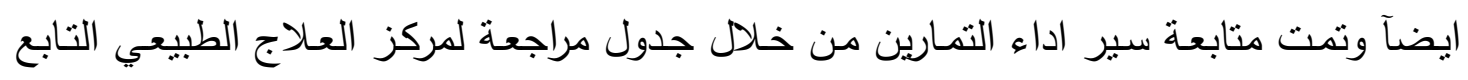

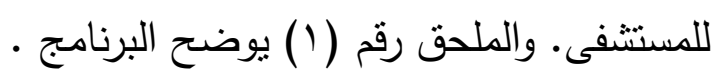
r- ب الوسائل الإحصائية ومعالجة البيانات

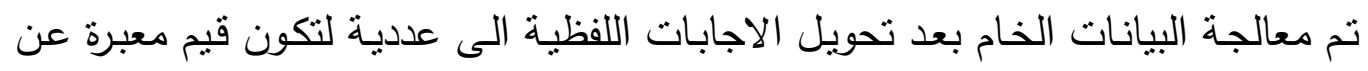

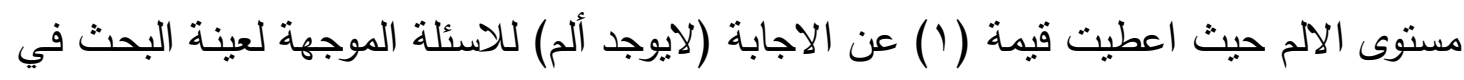

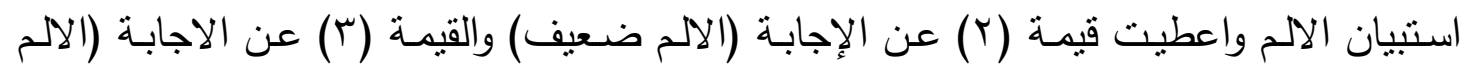

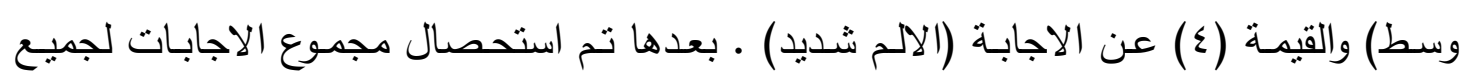

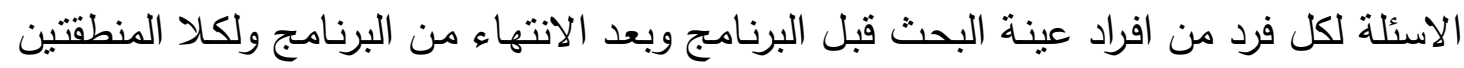

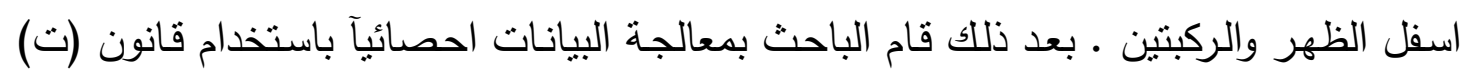

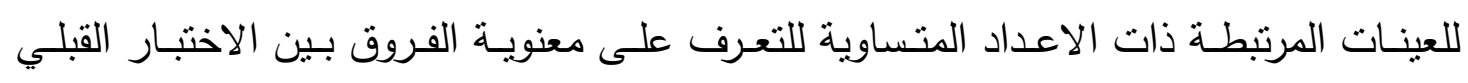

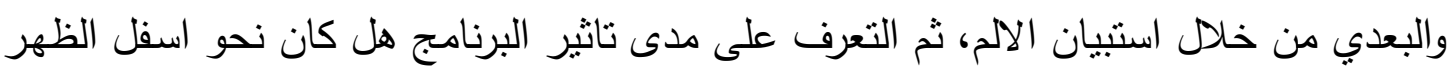

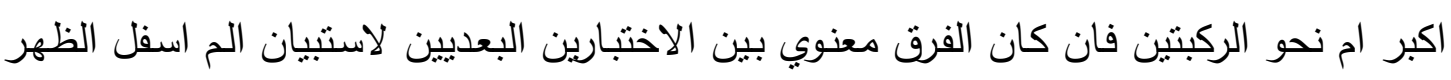

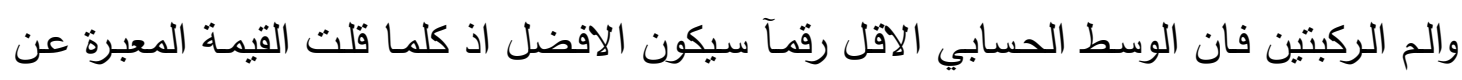

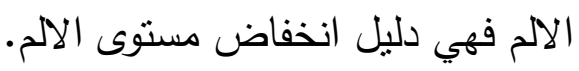
ب-ه الوسائل الإحصائية :

واستخدم الباحث الوسائل الاحصائية الاتية :

1.الوسط الحسابي

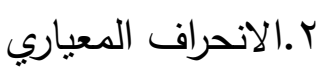

r.قانون (ت) للعينات المرتبطة (التكريتي والعبيدي ـ99 99 ()).

צ - عرض النتائج ومناقشتها

(1) - الجدول رقم

يبين أعمار وأوزلن واطوال ومدة الحمل وتسلسل الحمل لاى عينة البحث

\begin{tabular}{|c|c|c|c|c|c|}
\hline تسلسل الحمل & مدة الحمل & الطول & الوزن & العمر & $ت$ \\
\hline$r$ & 0 & 199 & Vr & rq & 1 \\
\hline 。 & 1 & $14 r$ & $v_{1}$ & $r_{1}$ & $r$ \\
\hline r & 0 & 109 & 79 & rr & $r$ \\
\hline
\end{tabular}

YIS 


\begin{tabular}{|c|c|c|c|c|c|}
\hline$\varepsilon$ & 7 & 171 & Vr & rq & $\varepsilon$ \\
\hline 9 & 7 & 171 & $\Lambda_{1}$ & $r$ & 0 \\
\hline 0 & $v$ & 171 & Vr & $r r$ & 7 \\
\hline 7 & $v$ & 109 & V & $r \leq$ & $v$ \\
\hline$\varepsilon$ & $v$ & 178 & $\vee \wedge$ & $r r$ & $\wedge$ \\
\hline 7 & 9 & 174 & 79 & $r \leq$ & 9 \\
\hline$r$ & 0 & 178 & 70 & $r \wedge$ & 1. \\
\hline$v$ & $\varepsilon$ & 104 & vo & $r$ & 11 \\
\hline$\varepsilon$ & 7 & 174 & Vr & ro & Ir \\
\hline$r$ & $V$ & IVr & $V \leq$ & $r r$ & Ir \\
\hline 0 & $\varepsilon$ & 178 & VV & r & $1 \varepsilon$ \\
\hline$r$ & 0 & 178 & 70 & $r r$ & 10 \\
\hline 7 & 7 & $|v|$ & N & $r$. & 17 \\
\hline$\varepsilon$ & 0 & 171 & 70 & rq & iv \\
\hline$r$ & 0 & 178 & VV & $r \leq$ & 11 \\
\hline$r$ & V & 170 & VV & $\mu$. & 19 \\
\hline 0 & 7 & 179 & vo & r & $r$. \\
\hline 0 & $v$ & 179 & $\vee \wedge$ & rq & YI \\
\hline$\varepsilon$ & 0 & 171 & vo & rV & YY \\
\hline$r$ & 7 & 190 & $V_{7}$ & $r v$ & rr \\
\hline
\end{tabular}

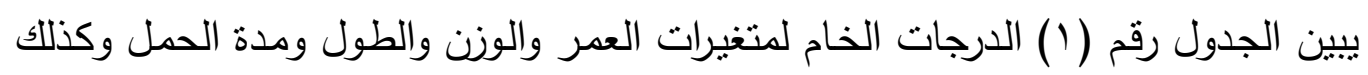

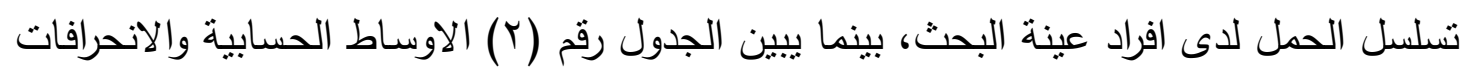

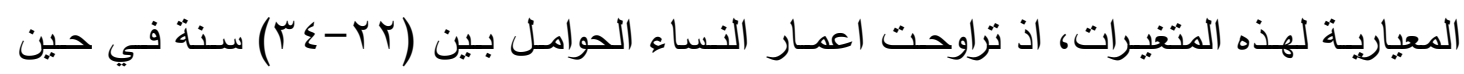

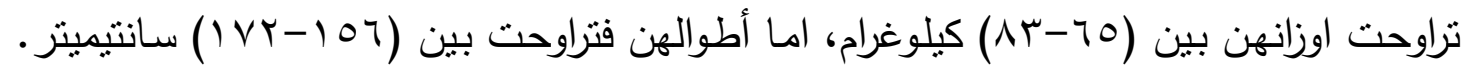

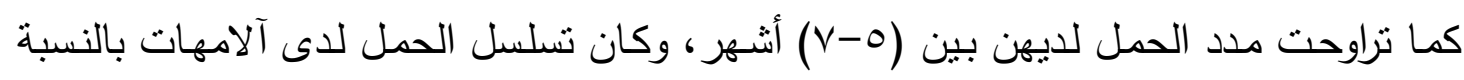

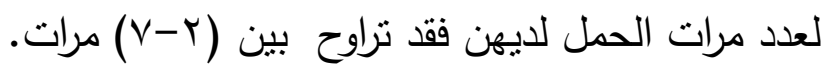

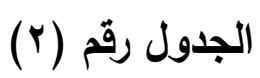

يبين الاوساط الحسابية والانحرافات المعيارية لاعمار واوزان واطوال ومدة الحمل وتسلسل الحمل لاى افراد عينة البحث

\begin{tabular}{|c|c|c|c|c|c|}
\hline تسلسل الحمل & مدة الحمل & الطول & الوزن & العمر & لائتفيرات الدوال \\
\hline$\varepsilon, 1 V$ & Y, Y Y & $170,1 \mathrm{~V}$ & $V \Psi, V \leqslant$ & $r \wedge, \leqslant \Lambda$ & الوسط الحسابي \\
\hline
\end{tabular}




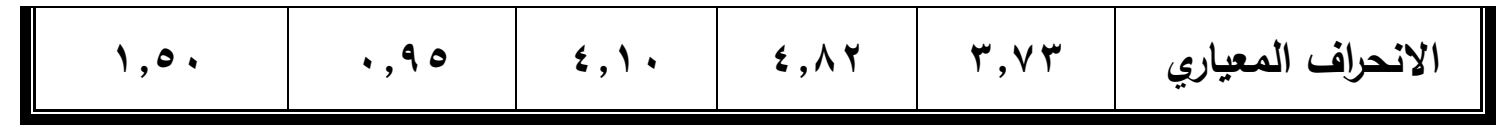

يبين الجدول رقم (r) الاوساط الحسابية الانحرافات المعيارية لاعمار واوزان واطوال ومدد

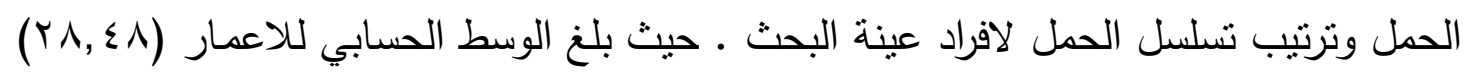

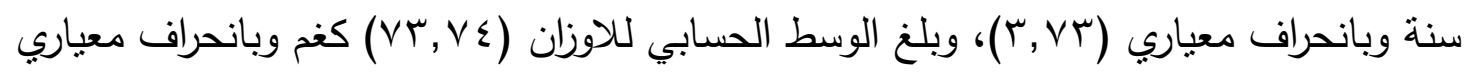

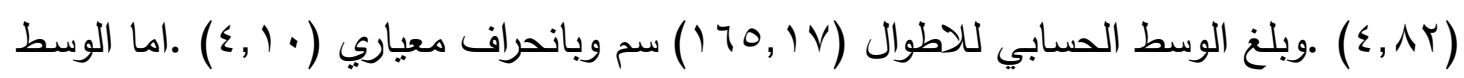

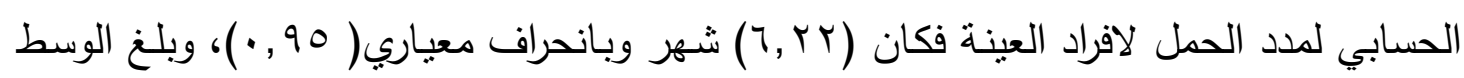

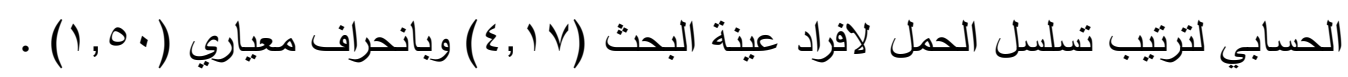
الجدول رقم (r) المبات

يبين الاوساط الحسابية والانحرافات المعيارية لاستبيان آلام اسفل الظهر والركبتين قبل

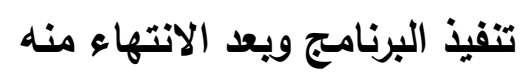

\begin{tabular}{|c|c|c|c|c|}
\hline الم أسفل الظهر & الم اسفل الظهر & الم الركبتين & الم الركبتين & المتغيرات \\
\hline$r r, \wedge v$ & 04,70 & Y1,97 & r & الوسط الحسابي \\
\hline 1,97 & $0, I V$ & $r, 1 \wedge$ & r,qV & الانحراف المعياري \\
\hline
\end{tabular}

يوضـح الجدول رقم (r) قيم الاوسـاط الحسابية والانحرافـات المعياريـة لاستبيانات الالم

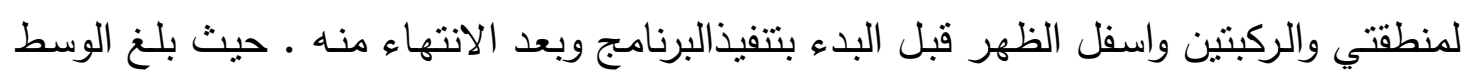

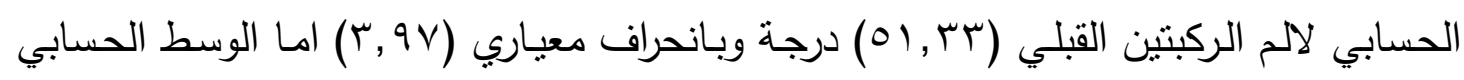

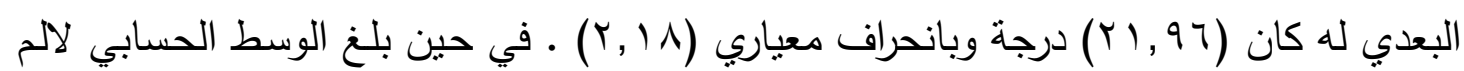

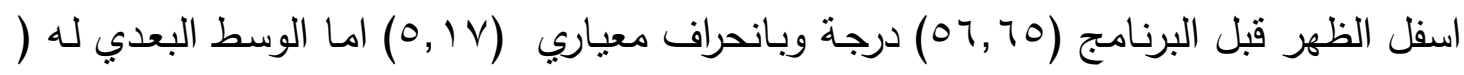
(Yr, AV

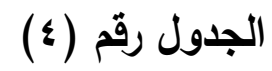

يين قيم (ت) المحتسبة بين استبيان الالم القبلي والبعدي لمنطقة اسفل الظهر ومنطقة

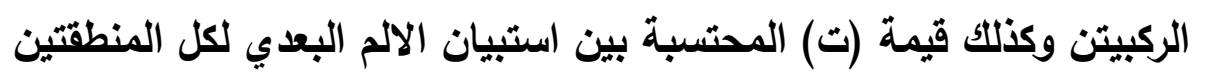

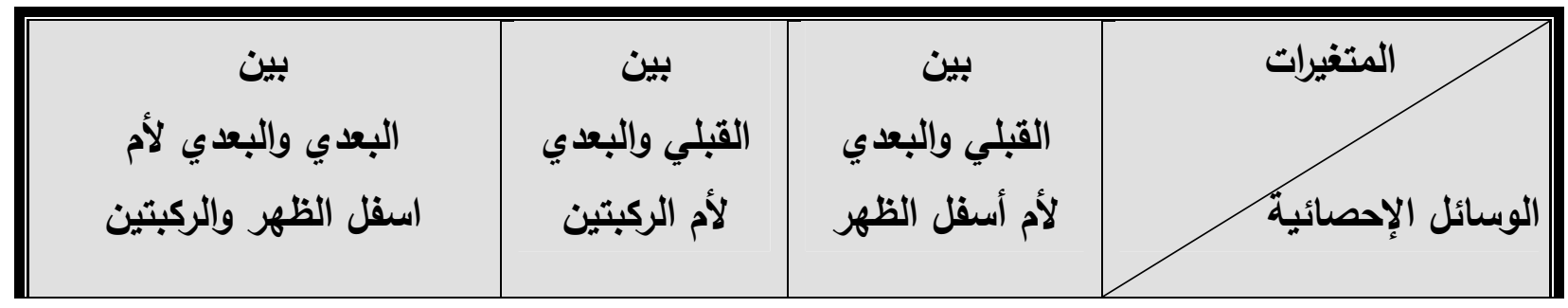




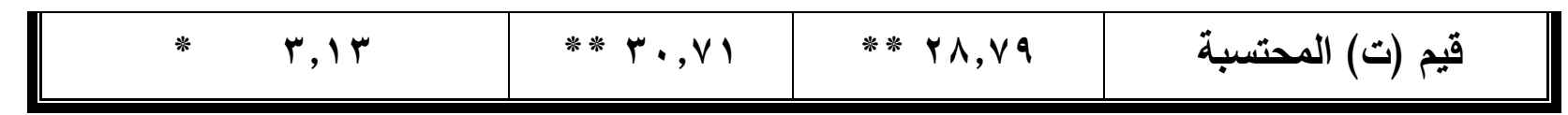

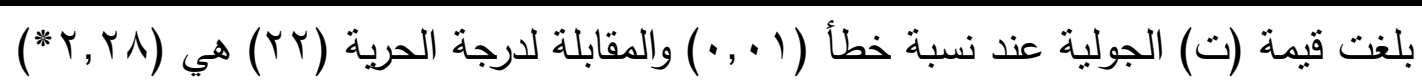
يتبين من الجدول رقم (ץ) قيم (ت) المحتسبة لاختبارات مستوى الآلم القبلية والبعدية لمنطقة

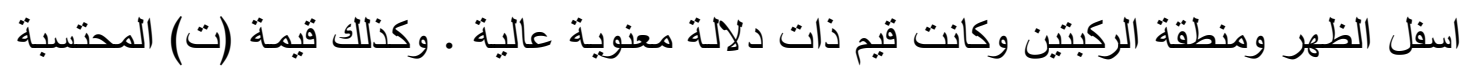

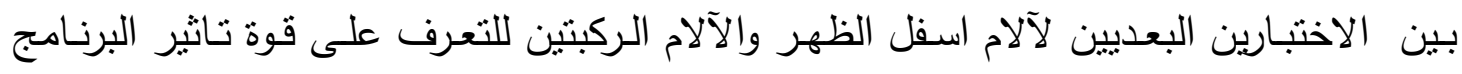
باتجاه تخفيف الم منطقة اسفل الظهر ام الركبتين كانت اكبر وكانت القيمة ذات دلالة معنوية ايضا وهي تدل على وجود فرق في تأثثر البرنامج على منطقتي الالم وبالعودة الى قيم الاوساط

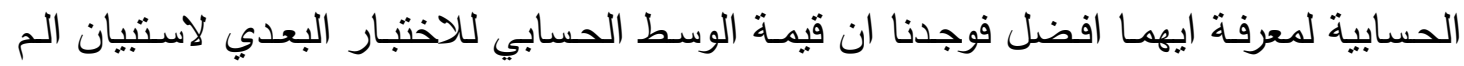
الركبتين هي (Y , 97) وهي اقل من قيمة الوسط الحسابي لاختبار استبيان الم اسفل الظهر

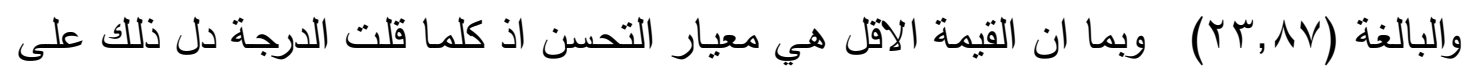

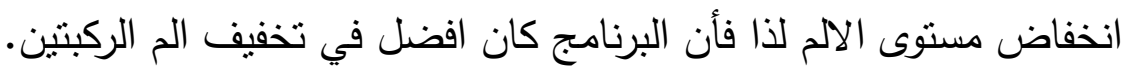
ويعزو الباحث القيمـة المعنويـة العاليـة للفروق الى فاعلية البرنـامج في تخفيف الآلام

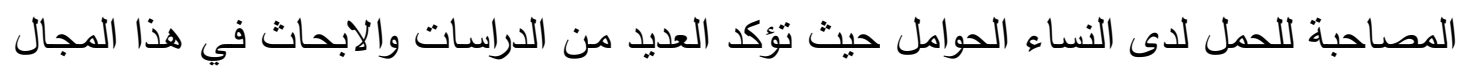

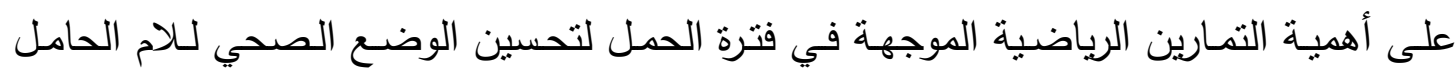

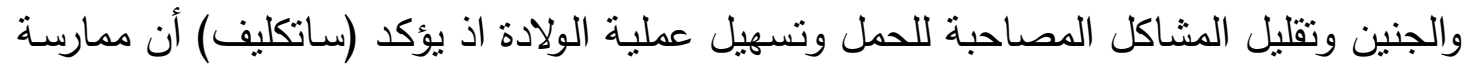

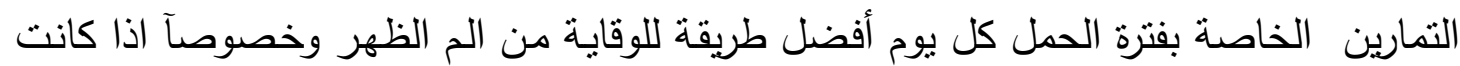

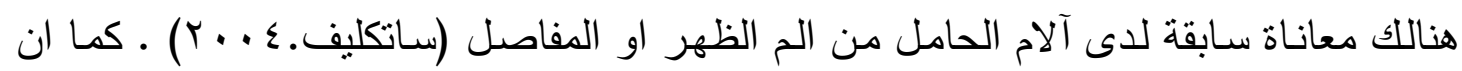
ممارسة التمارين لمرة او مرتين في اليوم بحيث يؤدى التمرين (0) مرات ويزداد التكرار بالتدريج

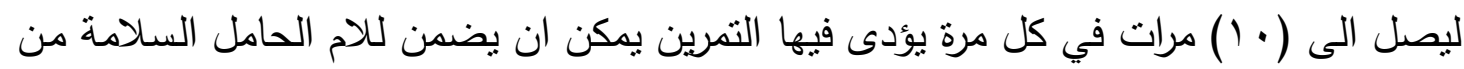

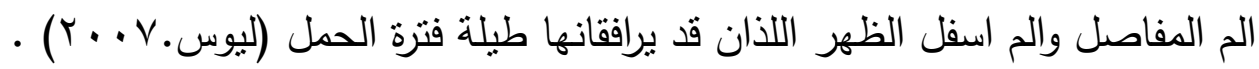
ويؤكد بعض الاطباء انه من الممكن تجنب او تقليل آلام مفاصل الاطراف السفلى وآلام

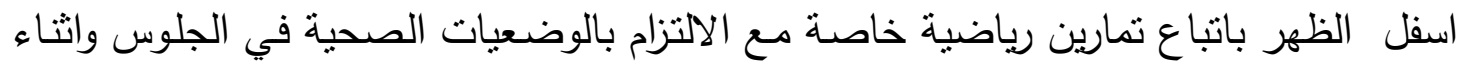

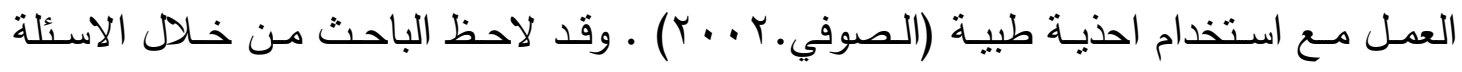

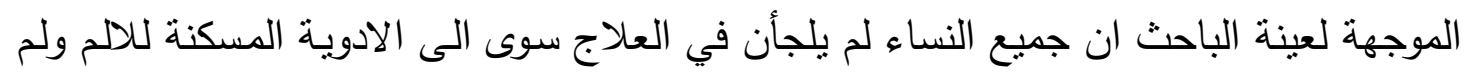

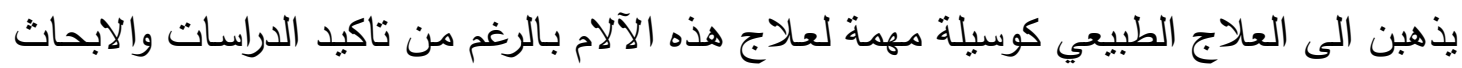

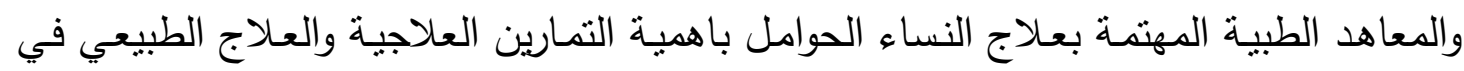

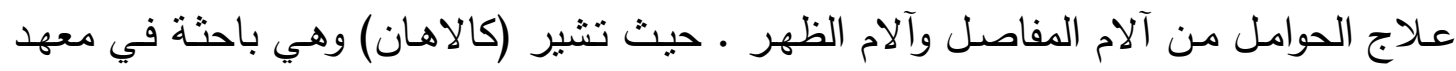
طب الرياضة النسائية في امريكا بأن الدراسات التي أجريت على الحوامل ممن يمارسن التمارين

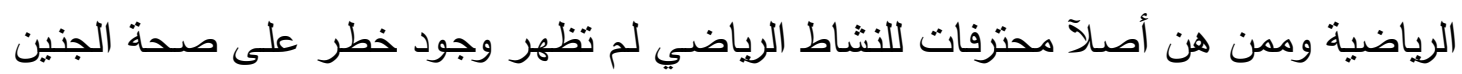


او آلام الحامل بسبب ممارستها للتمارين الرياضية وحتى الرياضة الثديدة بل كانت ايجابية في

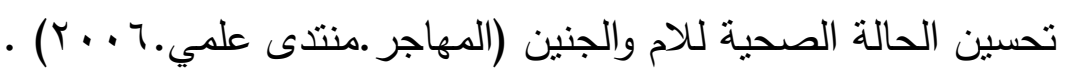

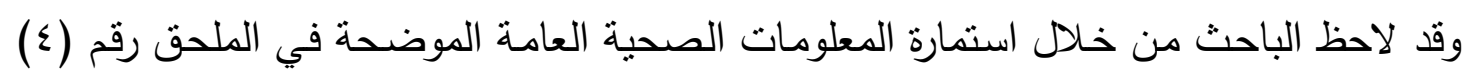

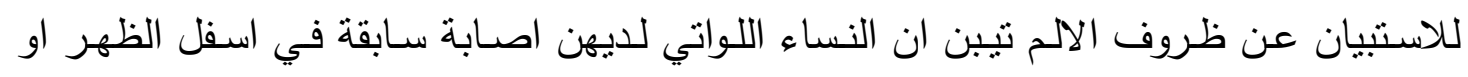

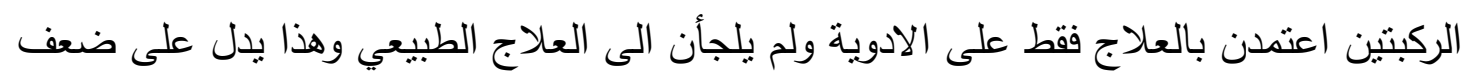

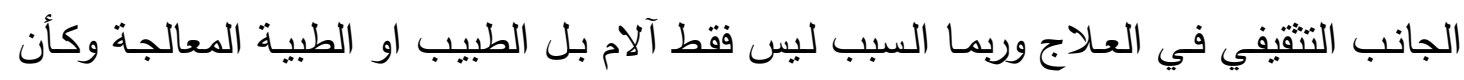

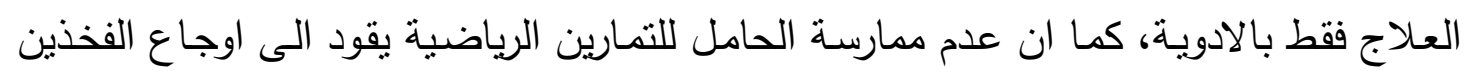

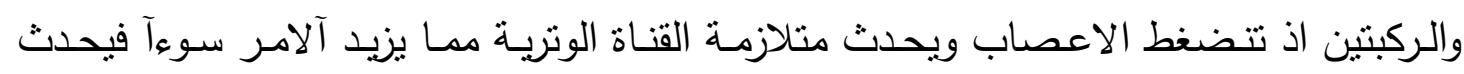
احتباس لسوائل الدم في مناطق الدفاصل وخصوصاً الاطراف ( Morris.1999).

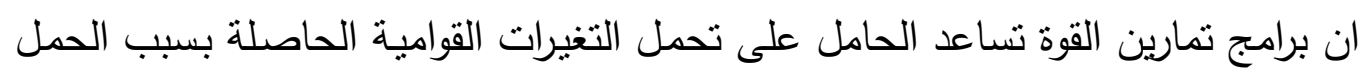
مع الزيادة في الوزن وكذلك آلام أسفل الظهر فضلا عن دور التمارين في تحويل الدم من الرحم

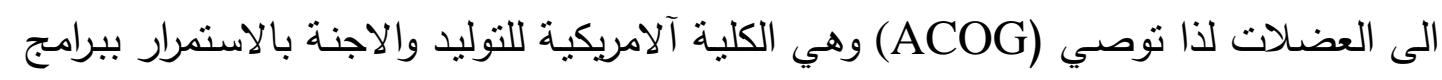

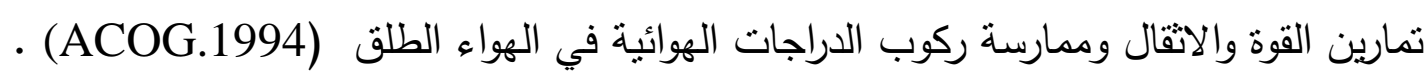

\section{•- الاستنتاجات والتوصيات \\ ه- 1 الاستنتاجات}

ا ـ إن لبرنامج التمارين الرياضية العلاجيـة تأثير ايجابي عالي في تخفيف آلام الركبتين وآلام

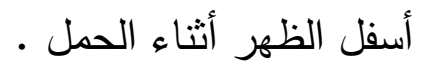

r. أفادة الدراسة أن للتمارين الرياضية الموجهة لاغراض علاهية تأنئن الثير ايجابي في تخفيف آلام

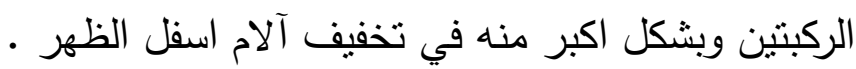

r-

ا ـ تعميم برنامج التمارين الرياضية العلاجية على المراكز الطبية التي تعنى بصحة آلام الحامل

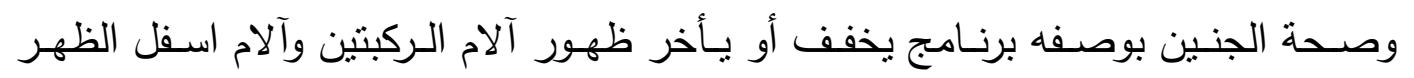
المرافقة للحمل . 
r. العناية بالتمارين الرياضية الموجهة خلال فترة الحمل لضمان حمل صحي خالي من المشاكل

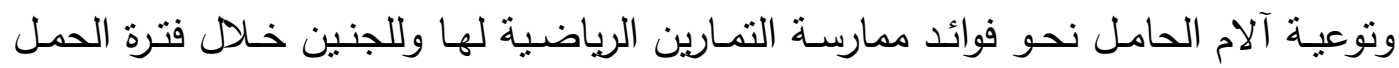

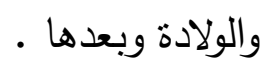

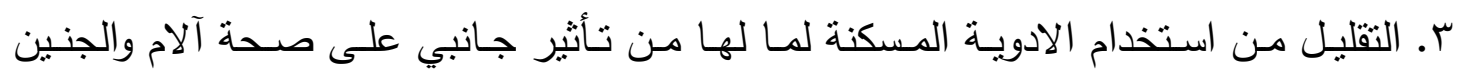

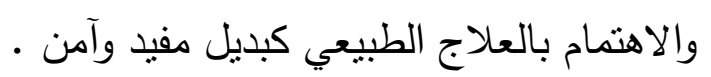

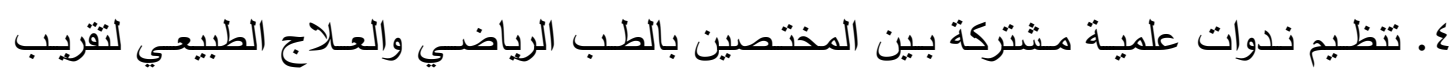
وجهات النظر العلية لما فيه مصلحة آلام الحامل والجنين .

\section{المصادر العربية والأجنبية}

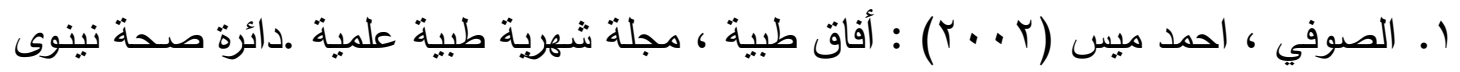

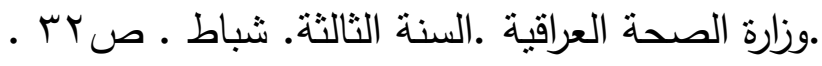
Y. التكريتي.وديع ياسين و العبيدي.حسن محمد ـ 1997 : التطبيقات الاحصائية في بحوث .

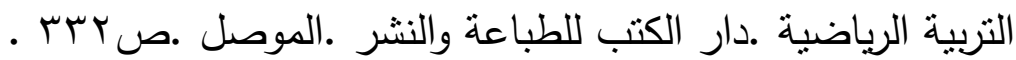

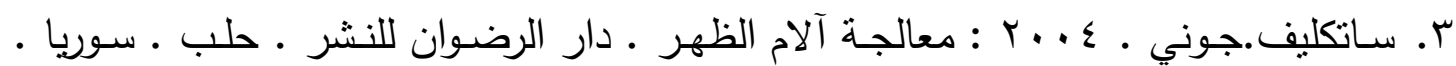
. $1 \leqslant \varepsilon$

ع. الصوفي.احمد ميسر ـ r . . T : مجلة أفاق طبية .مجلة شهرية طبية علمية .دائرة صحة

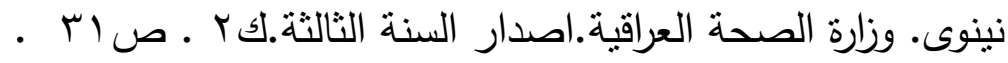
ه. طبيب دوت كوم ـ ؟ . . ب : موضوع الم الظهر ـ منشور على الشبكة العالمية للاتصالات. . 20 T. قناوي .محمود ـ ^ . . ץ : "البحث عن آلام اسفل الظهر" ـ مقالة طبية منشورة .موقع اشراقة

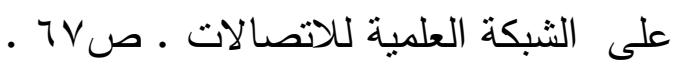
V. كلاب .جيمس ـ 1919 : "تأثثر الجهد الهوائي الموجهة على صحة الحامل والجنين" .

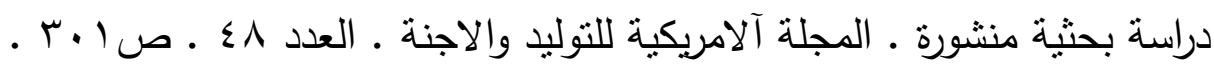

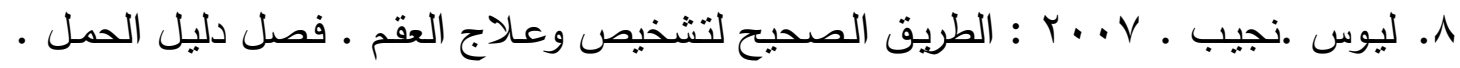

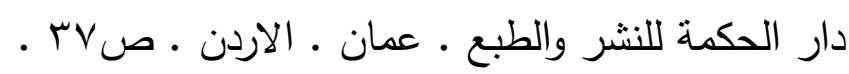
9. المهاجر موقع المنتديات الاسيوية ـ ؟ . . ب : موضوع الحمل والتمارين الرياضية ـ منشور

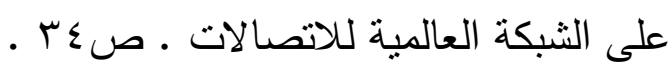

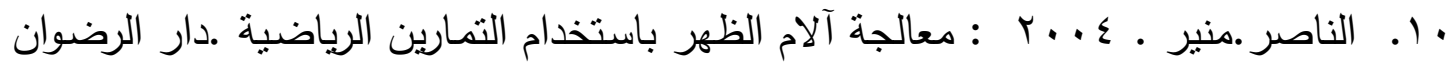

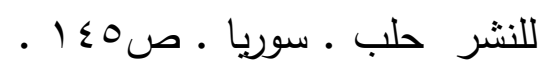


11. American College of Obstetrics and Gynecology Guidelines for exercise During Pregnancy and the Postpartum Period; ACOG Technical Bulletin 189. Washington. DC. ACOG. 1994.p189.

12. James H.. Bimmer: Fitness and Rehabilitation Programs for Special Population. WCB. Brown and Bench Mark publishers. printed in the USA. 1994.p300.

13. Jar ski RW. Triplett DL: The risks and Benefits of exercise during Pregnancy. JFAM pact 30; 185. 1990.p185.

14. Morris B. Mellion MD.: Sports Medicine Secrets. 2nd.edition. Hanley and Belfus. INC. Philadelphia for library of congress. 1999.p45.

\section{الملحق (1)}

\section{( برنامج التمارين العلاجية )}

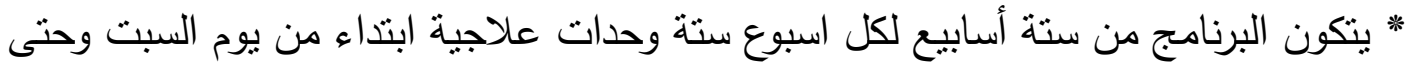

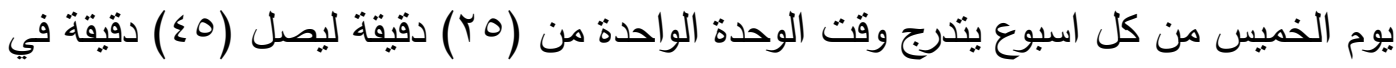

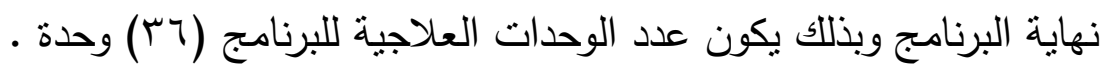

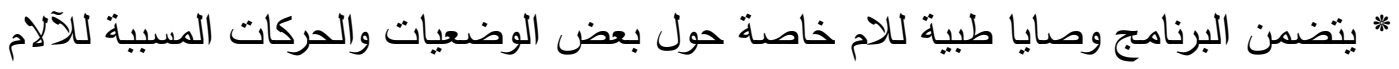

$$
\begin{aligned}
& \text { كطريقة النوم وطبيعة السرير والسطح المستخدم ونوعه وشكله فضلا عن مزاولة بعض الئه المهام } \\
& \text { البيتية وتجنب المؤذب منها . }
\end{aligned}
$$

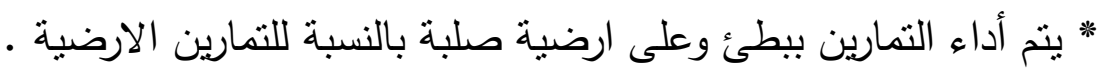




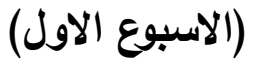 \\ تمارين أسفل الظهر}

التمرين الاول: ( الوقوف والظهر بوضع مستقيم والرجلين ومنباعدتين بمسافة عرض الحوض والقدمين منفرجتين للخارج واليدين ماسكتين لاعلى مسند الكرسي او اي شي ثابت ) ثني الركبتين

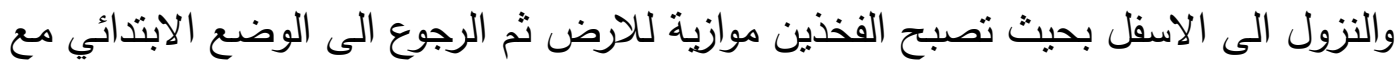

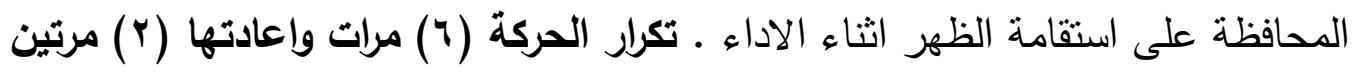

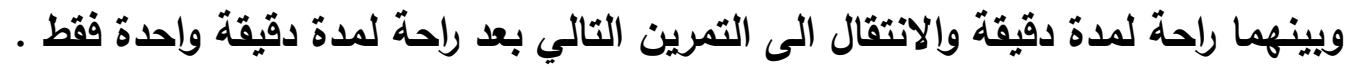
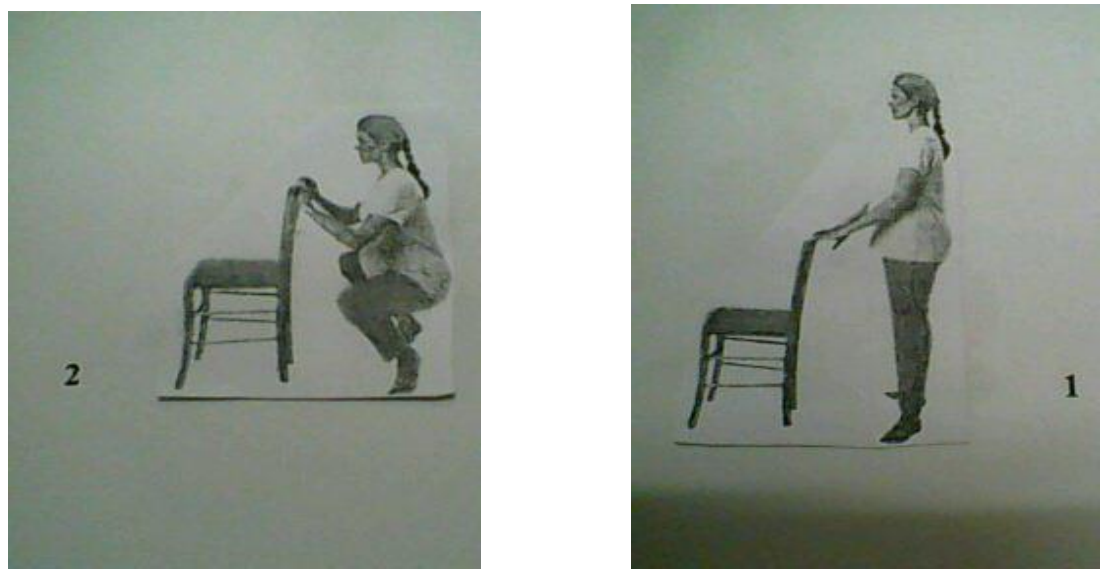

التمرين الثاني: ( الوقوف - فتحا اب الرجلين متباعديتن بمسافة عرض الحوض تقريبا ) رفع

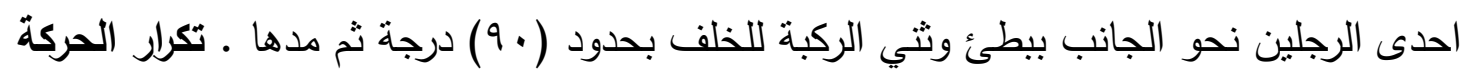

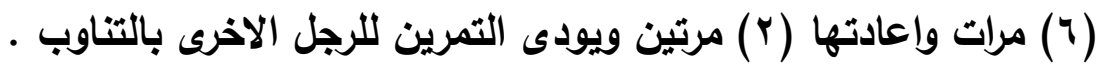

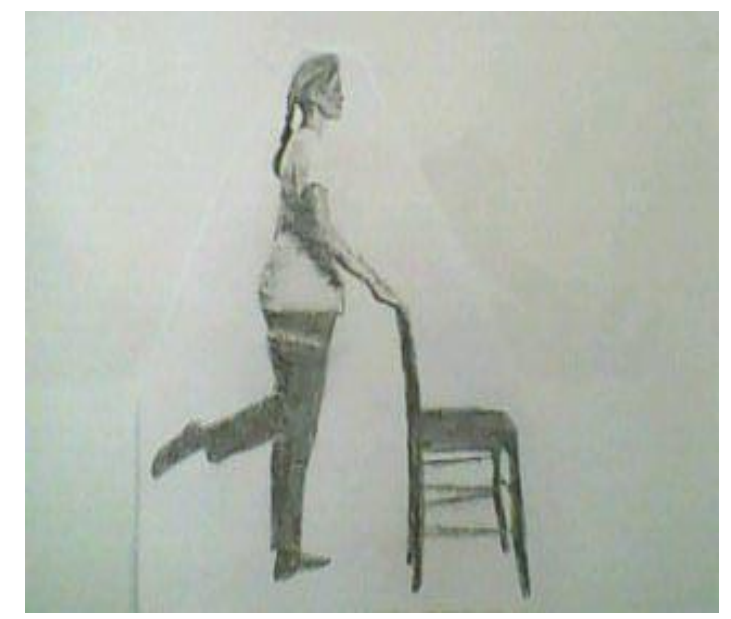


التمرين الثالث: ( الجلوس على الاربع اي تقاطع الرجلين ) فتل الجذع لاحد الجانبين مع وضع

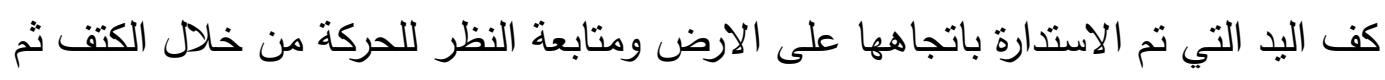

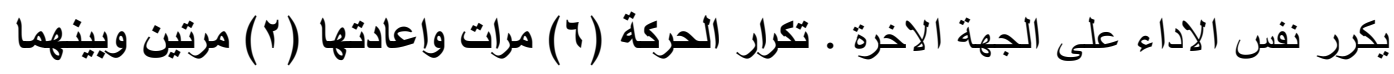

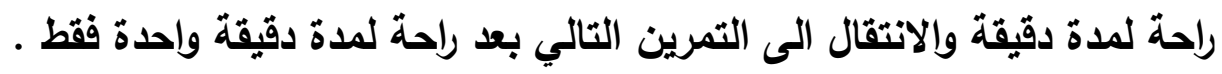

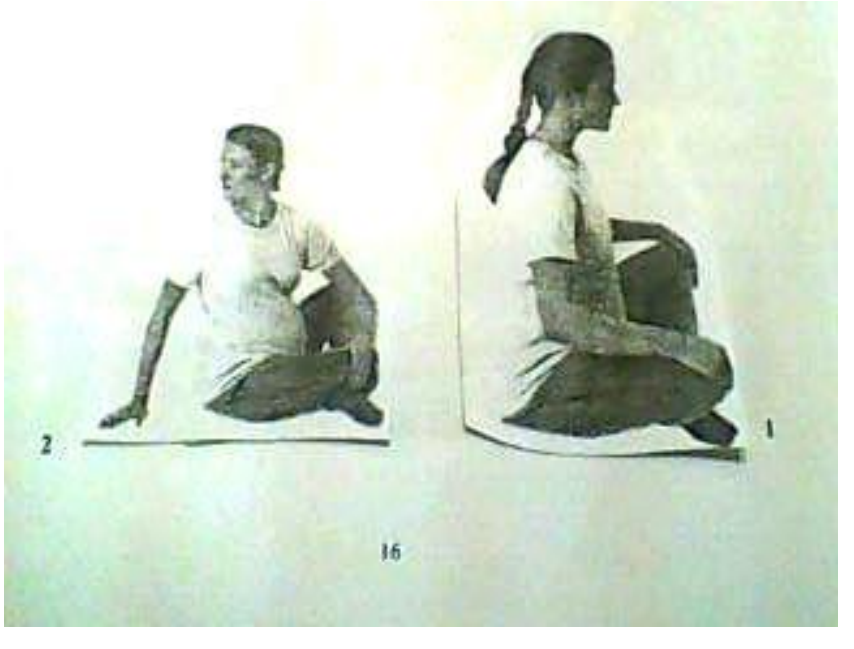

التمرين الرابع: ( الجلوس الطويل اي الرجلين ممدودة على الارض ومنباعدة عن بعضها

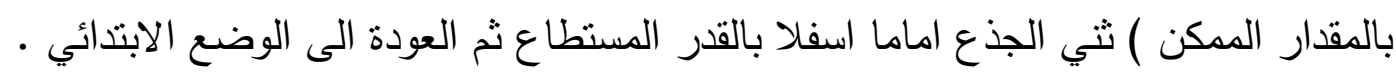

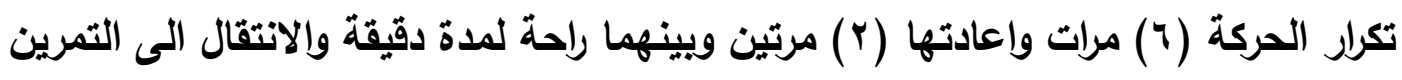

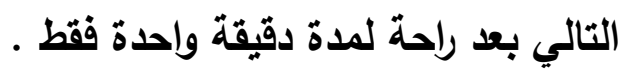
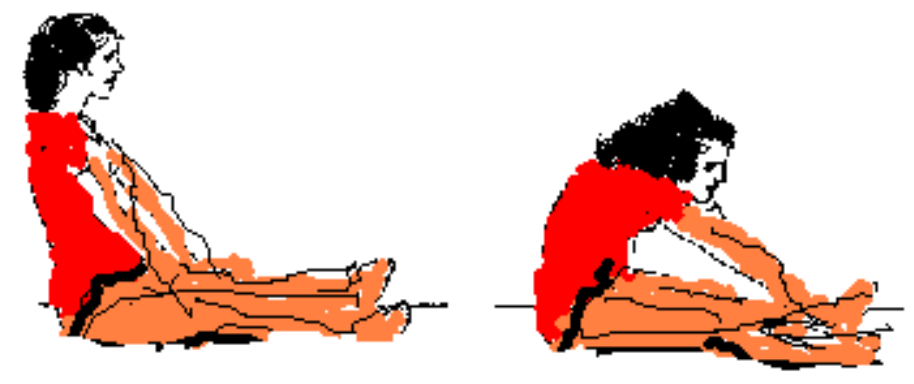

1

التمرين الخامس: ( الاستلقاء على الارض ) رفع الراس والكتفين بالقدر المككن عن الارض ثم

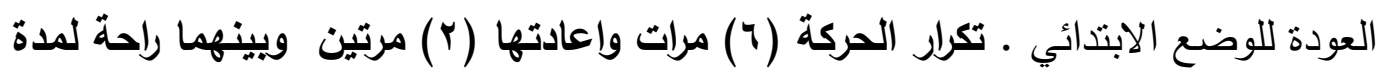

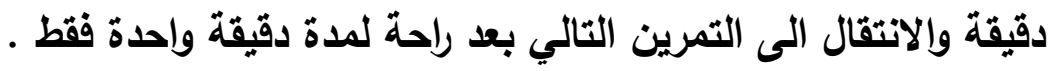




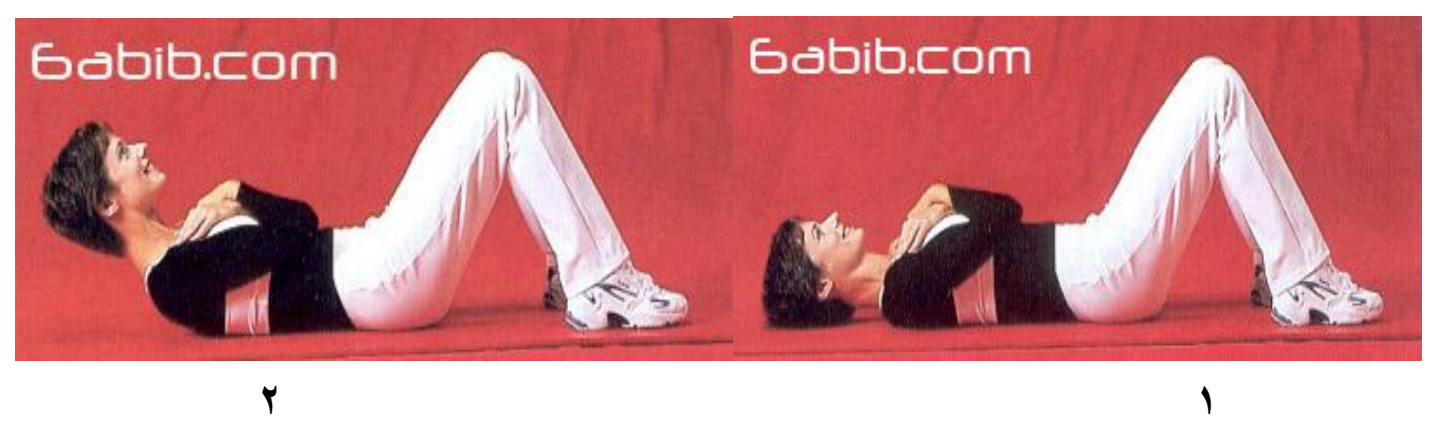

التمرين السادس: ( الاستلقاء والركبتين مثثيتين والاستتاد على القدمين ) رفع الحوض عن الارض بالقدر الممكن ثم العودة للوضع الابتدائي ـ تكرار الحركة (؟ ) مرات واعادتها (†) مرتين وينيهما راحة لمدة دقيقة والانتقال الى التمرين التالي بعد راحة لمدة دقيقة وإحدة فقط

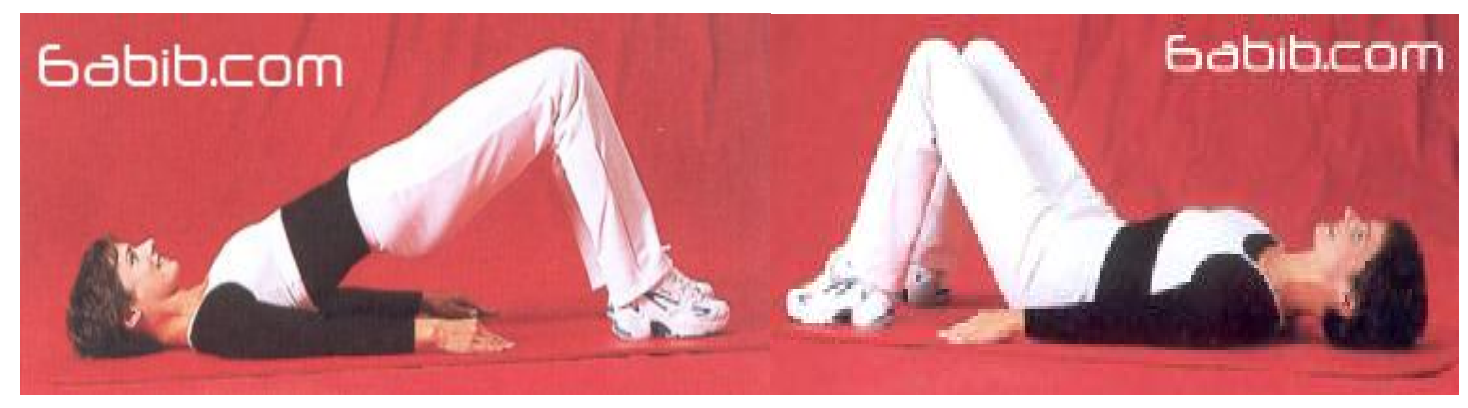

r

التمرين السابع: ( الاستلقاء على الظهر والرجلين بشكل عمودي على الجسم اي الفخذين والساقين مع القدمين مستتدة على الكرسي ليصل مفصلي الركبتين لزاوية ( • 9) درجة للاسترخاء وسحب وتمطية عضلات اسفل الظهر والبقاء بالوضع لمدة (•) دقائق

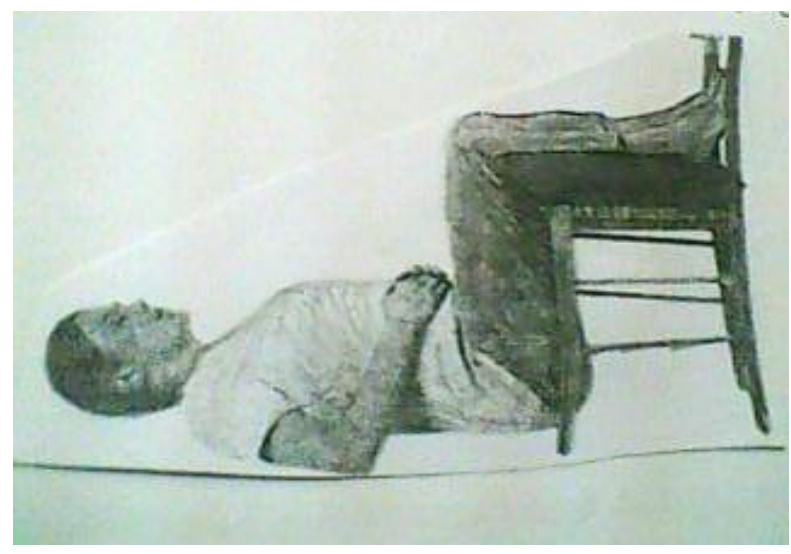

\section{تمارين الركبتين}

التمرين الثامن: (التمن الجلوس الطويل اي الرجلين ممدودة 
وضع قطعة من القماش على شكل رولة اسطوانية تحت مفصل احدى الركبتين ) شد عضلات

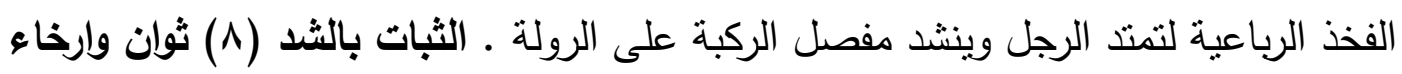

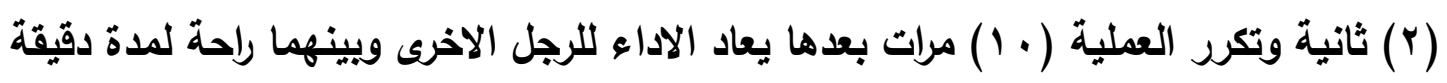

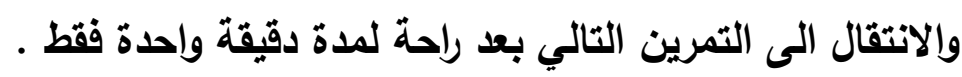

\section{( الأسبوع الثاني )}

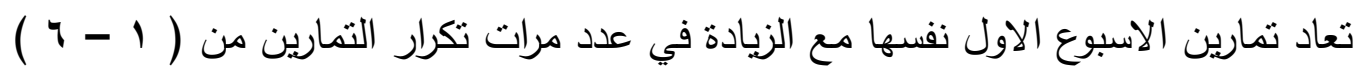

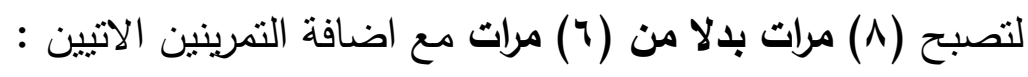

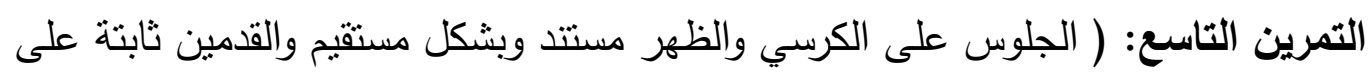
الارض وضع وسادة بين الرجلين في منطقة الركبتين ) شد الرجلين سوية باتجاه الوسادة ـ الثبات

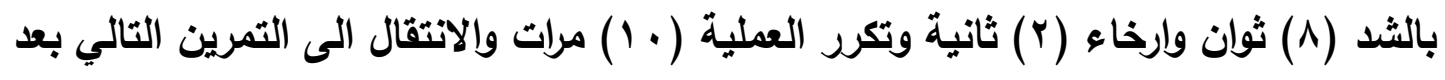

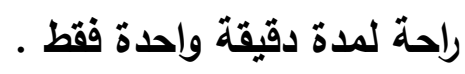

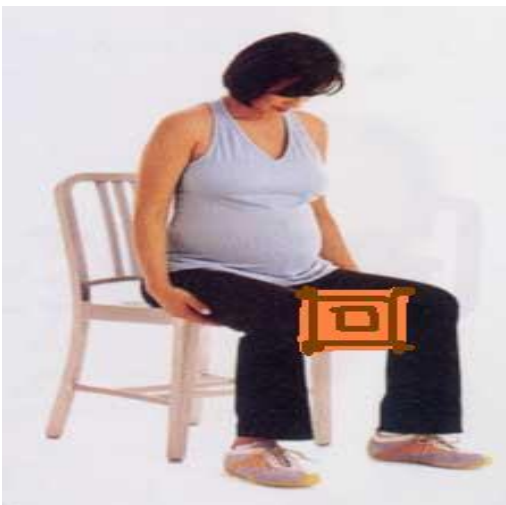

التمرين العاشر : ( نفس الوضع الابتدائي للتمرين التاسع الا ان الوسادة نوضع بجانب احد

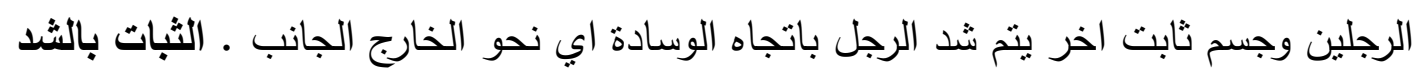

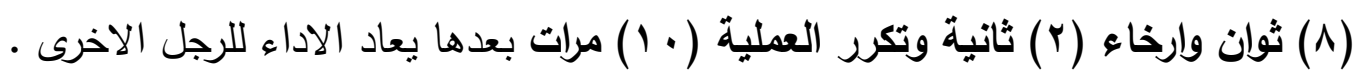




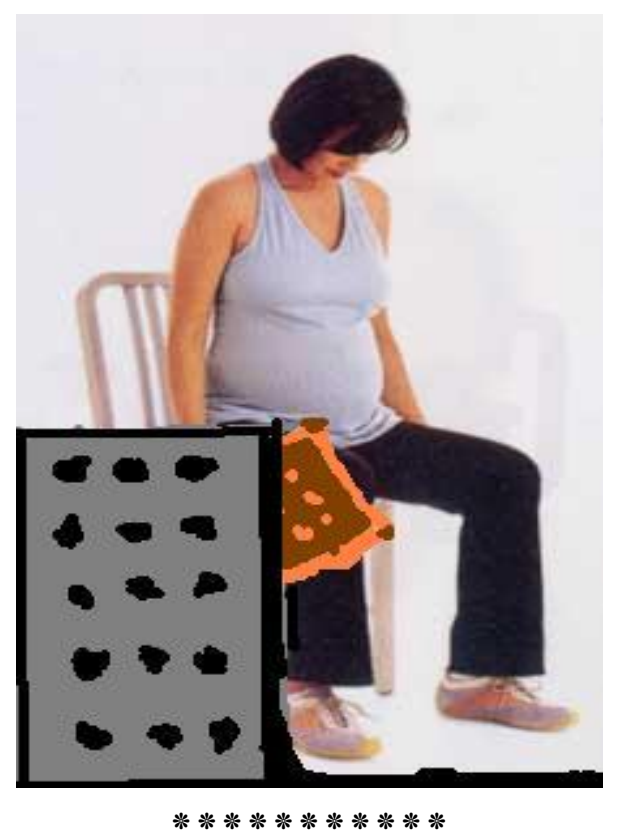

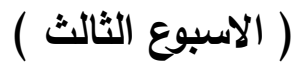

تعاد تمارين الاسبوع الثاني نفسها مع التغيير في التمارين من ( 1 - ـ ـ ( ) ليصبح تكرار

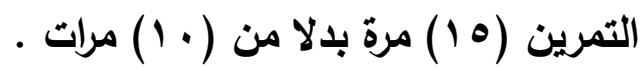

\section{( الاسبوع الرابع )}

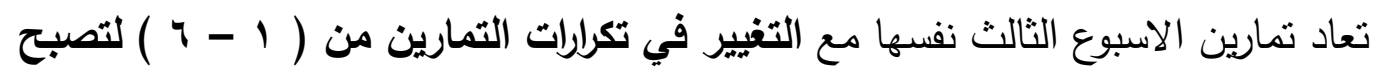
( • (1) مرات بدلا من (^) مرات ويضاف التمرينين الاتيين:

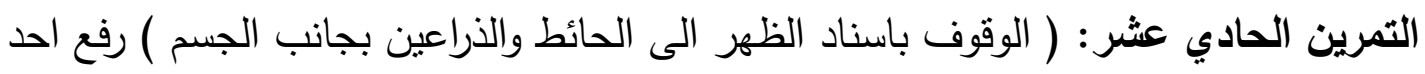
الرجلين بحيث يصل مفصل الركبة بمستوى الحوض ويكون الفخذ موازيا للارض ثم خفضه بـانه

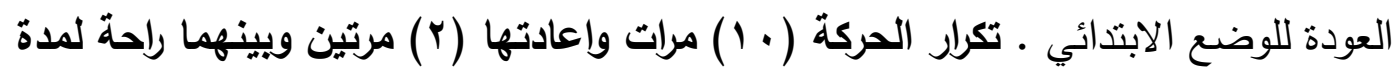

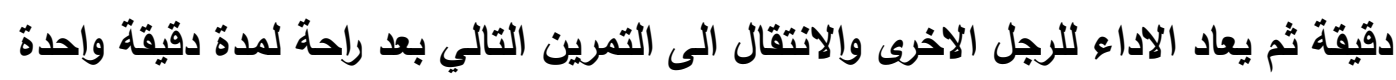

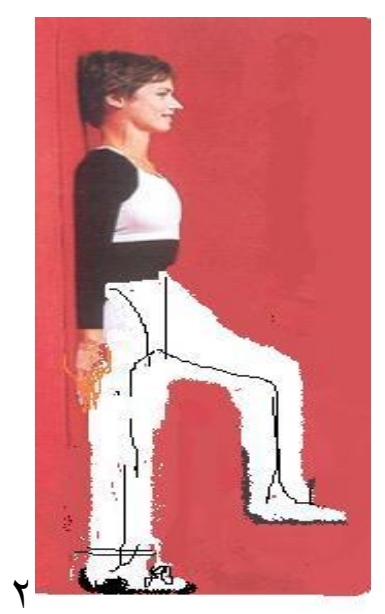
فقط .

Tro 
التمرين الثاني عثر: (الوقوف باسناد الظهر الى الحائط ) ثي الركبتين بالقدر الممكن ثم مدها

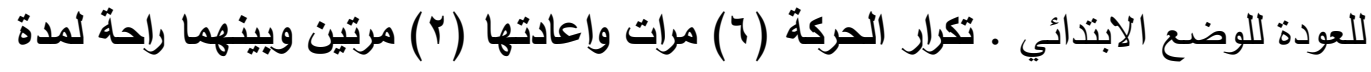
دقيقة والانتقال الى التمرين التالي بعد راحة لمدة دقيقة واحدة فقط . لماتئ
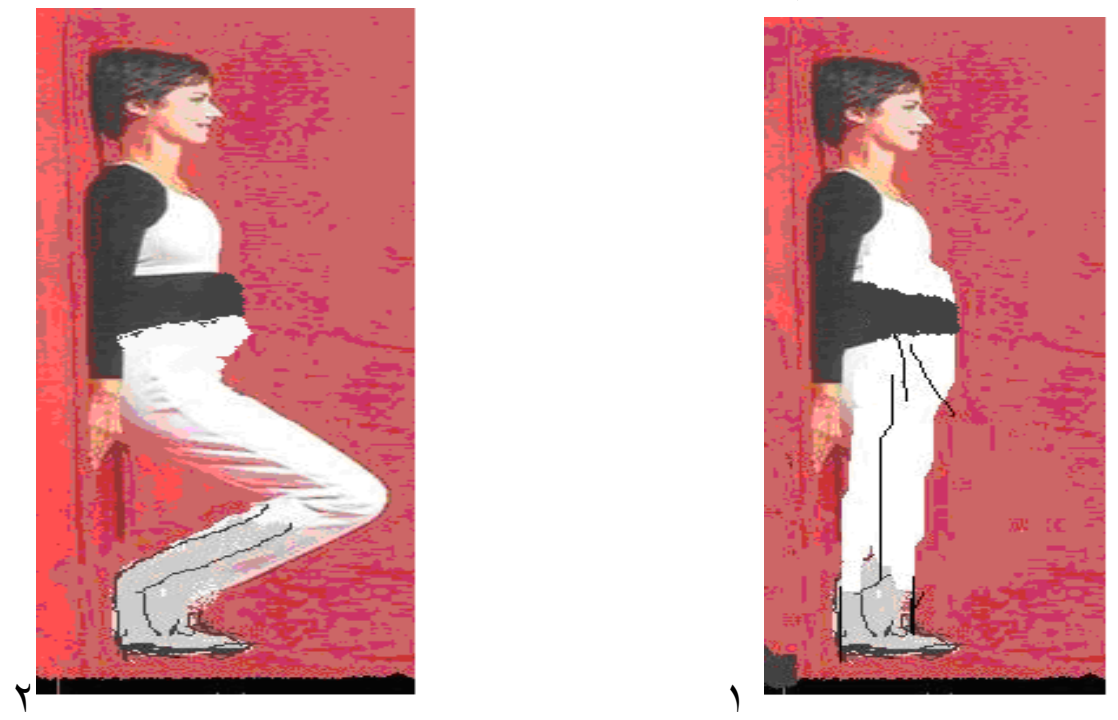

\section{( الاسبوع الخامس )}

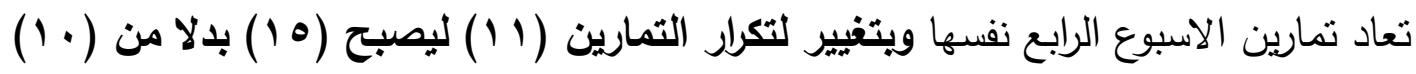

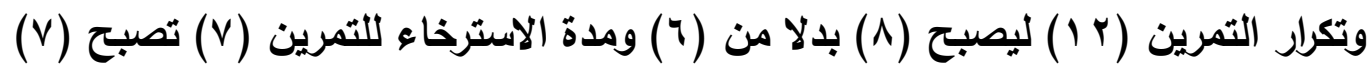

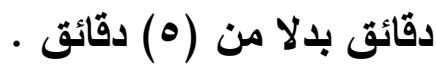

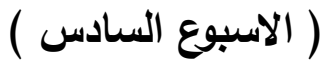

تعاد تمارين الاسبوع الخامس نفسها ويتغيير بتكار التمرين (r ( ) ليصبح ( • ( ) مرات بدلا من

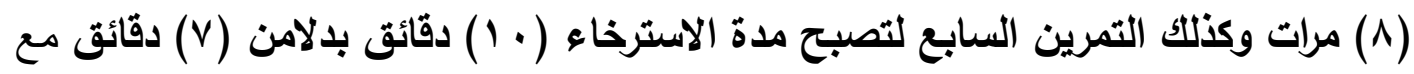

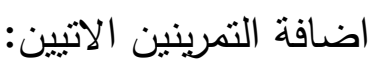
التمين الثالث عشر : ( استلقاء على جانبك الأيمن) بحيث تكون ركبة الرجل اليمنى مثثية بحدود

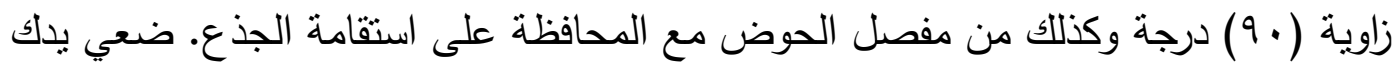
اليمنى على الأرض أمام صدرك واسندي رأسك على وسادة وتكون الرجل اليسرى مستقيمة وتثنكل زاوية قائمة تقريباً مع البطن وتوازي الفخذ الايمن ـ استرخي وخذي نفسك والثي ، ثم أخرجيه

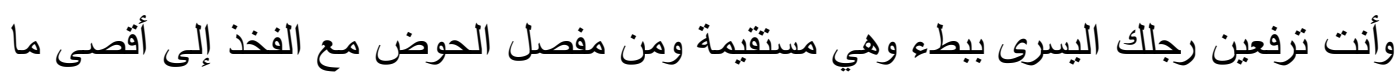


تستطيعين مع إبقاء قدمك مشدودة ( أصابع قدمك تتجه نحو بطنك ) ، ويكون كاحلك الداخلي

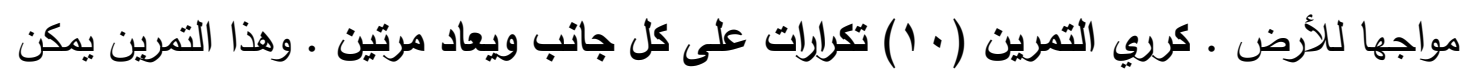

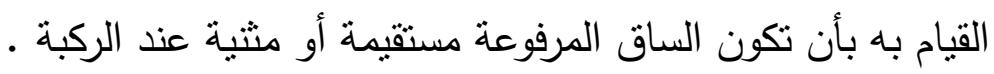
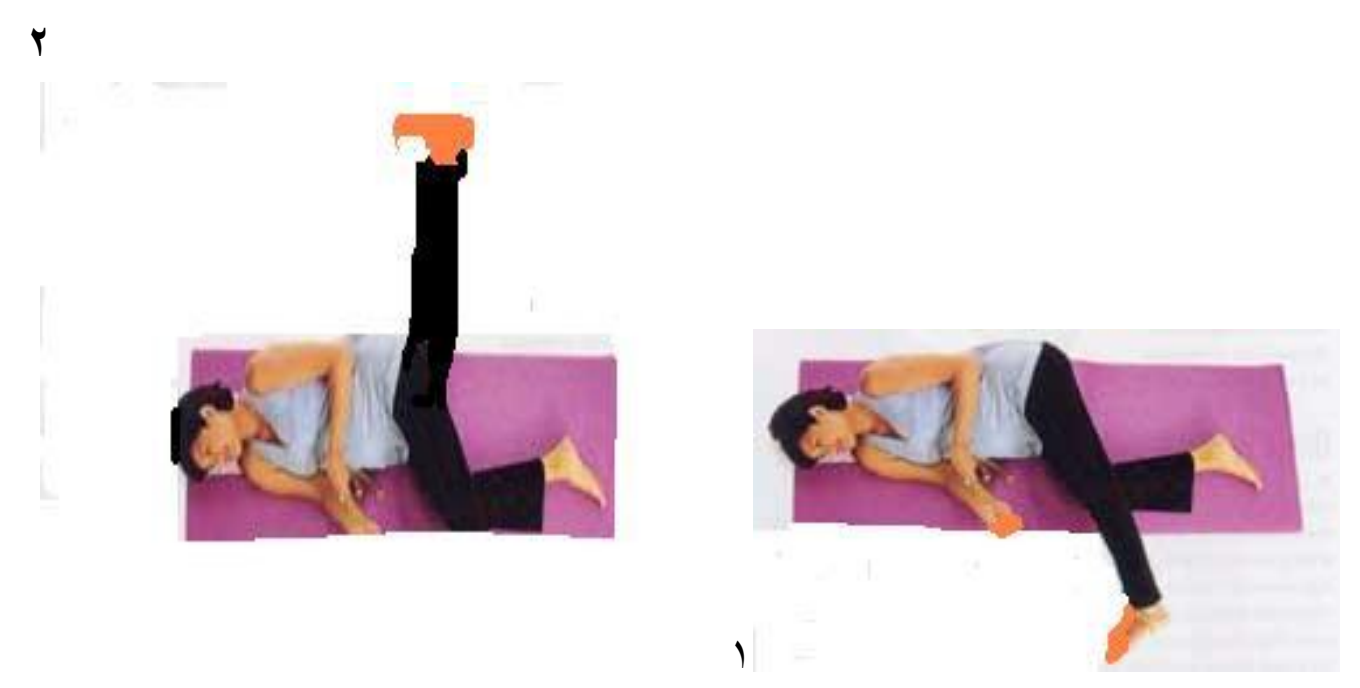

الملحق(ب)

استمارة استبيان درجة الالم في اسفل الظهر

\begin{tabular}{|c|c|c|c|c|c|}
\hline \multicolumn{4}{|c|}{ 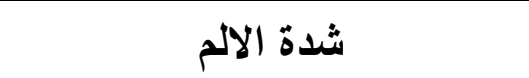 } & \multirow{2}{*}{ الاسئلة } & \multirow[b]{2}{*}{$ت$} \\
\hline لايوجد & 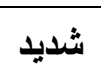 & وسط & ضعيف & & \\
\hline & & & & هل الالم موجود في وقت الراحة عند الوقوف & 1 \\
\hline & & & & هل الالم موجود عند النوم على الظهر & $r$ \\
\hline & & & & هل الالم موجود اثناء الجلوس الاعتبادي لفترة طويلة & $r$ \\
\hline & & & & هل الالم موجود عند الاستلقاء على احد الجانبين & $\varepsilon$ \\
\hline & & & & هل يظهر الم عند رفع الرجلين ممدودتين الى الاعلى & $\circ$ \\
\hline & & & & هل الالم موجود عند اداء الاعمال الحياتية اليومية & 1 \\
\hline & & & & هل الالم موجود عند حمل الاششياء التقيلة & v \\
\hline
\end{tabular}




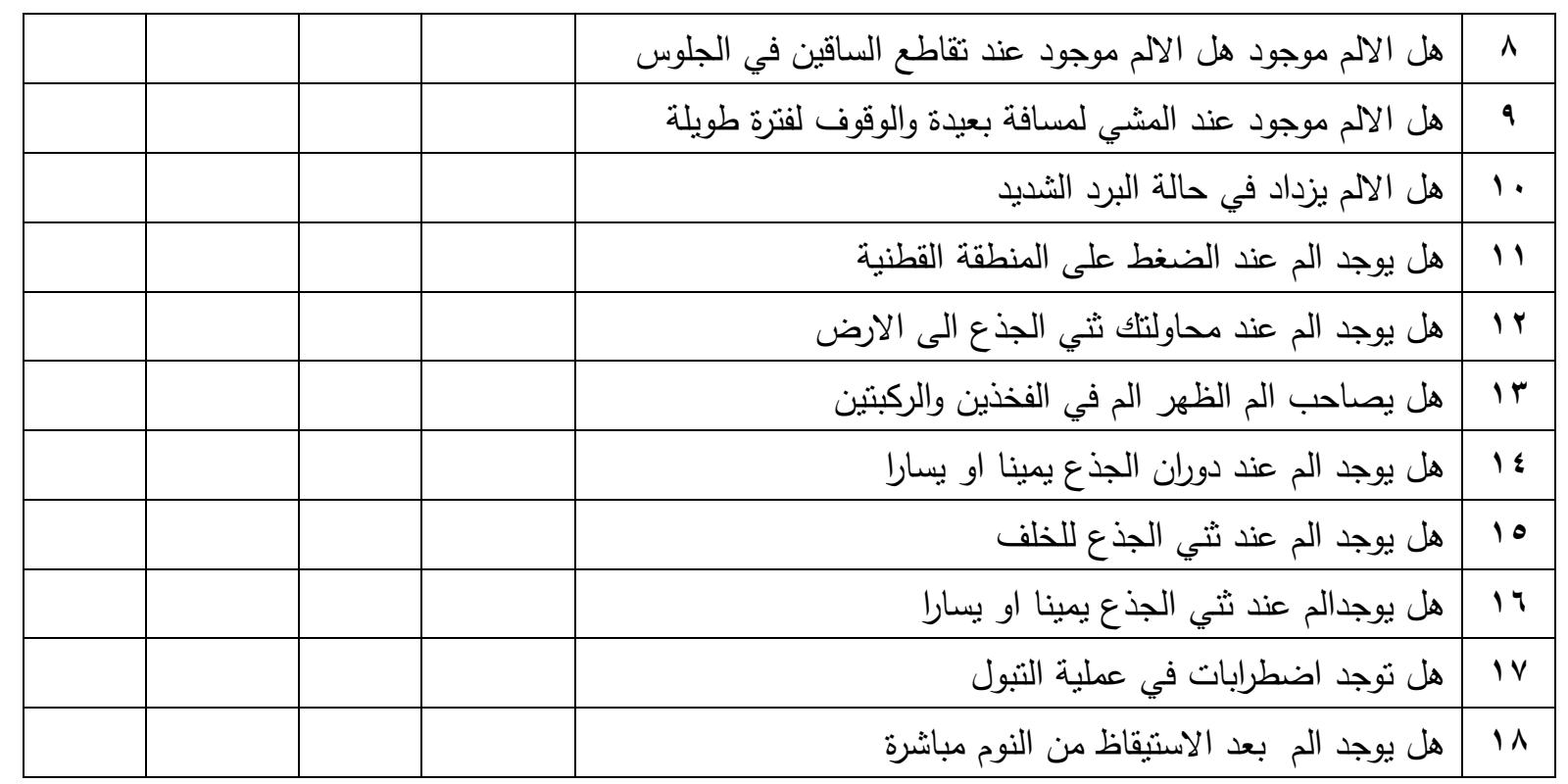

الملحق(r)

استمارة الاستبيان درجة الالم في الركبتين

\begin{tabular}{|c|c|c|c|c|c|}
\hline \multicolumn{4}{|c|}{ شُدة الالم } & \multirow{2}{*}{ الاسئلة } & \multirow[b]{2}{*}{ ث } \\
\hline 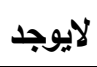 & 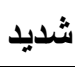 & وسط & ضعيف & & \\
\hline & & & & هل الالم موجود في وقت الراحة & 1 \\
\hline & & & & هل الالم موجود عند ثتي الركبتين بالكامل & r \\
\hline & & & & هل الالم موجود اثتاء الجلوس الاعتيادي & $r$ \\
\hline & & & & هل الآلم موجود هل الالم موجود عند تقاطع الساقين بالجلوس & $\varepsilon$ \\
\hline & & & & هل يظهر الم عند رفع الرجلين ممدودتين الى الاعلى & $\bullet$ \\
\hline & & & & هل الالم موجود عند المشي لمسافة بعيدة & 9 \\
\hline & & & & هل الالم موجود عند حمل الاثشياء والمشي بها & V \\
\hline & & & & هل الالم موجود بعد القيام من الجلوس لفترة طويلة او النوم & $\wedge$ \\
\hline
\end{tabular}




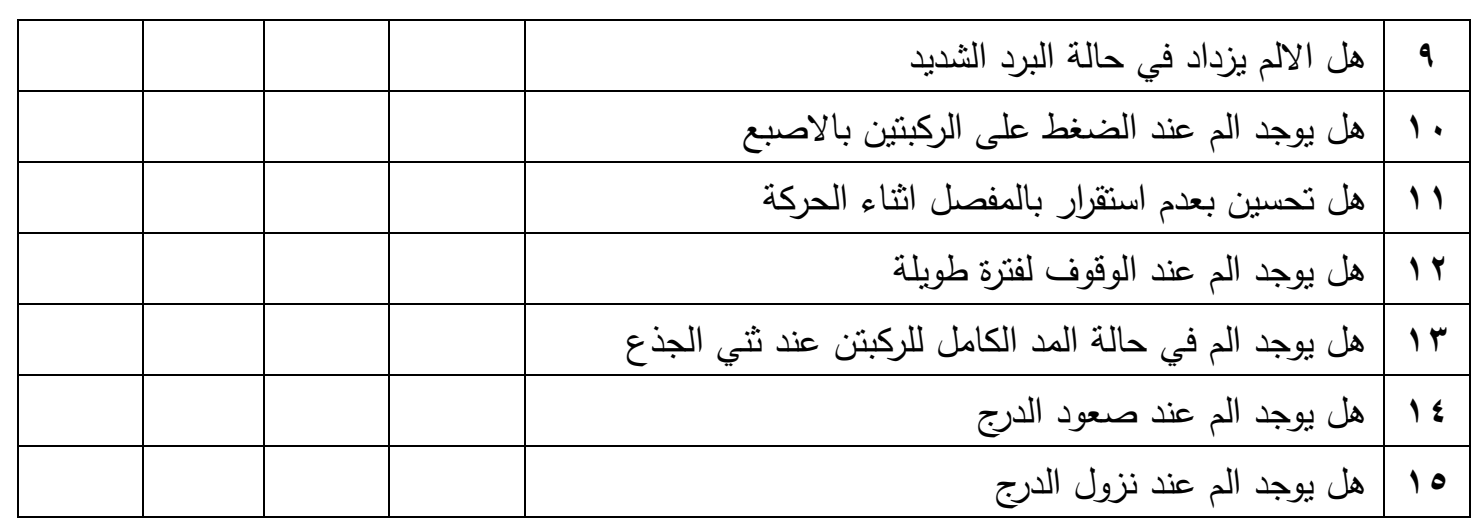

\section{الملحق( ) )}

استمارة المعومات

في النية اجراء البحث الموسوم (( اثر برنامج علاجي لتخفيف آلام اسفل الظهر وآلام الركبتين لاى النساء الحوامل )) • نرجو التفضل بالاجابة عن الاسئلة بدقة وموضوعية وذلك بوضع اشارة ( / ) امام العبارة المناسبة للك وملئ الفراغات بالمعلومات المطلوبة والمناسبة ـ شاكرين تعاونكم مع التقدير - معام

\section{المعلومات}

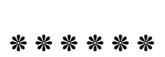

الوزن:

العمر:

الاسم:

الطول:

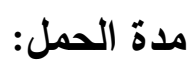

المهنة:

rrq 


$$
\begin{aligned}
& \text { "نوع الحذاء المستخدم: كب عالي وسط مسطح داء رياضي }
\end{aligned}
$$

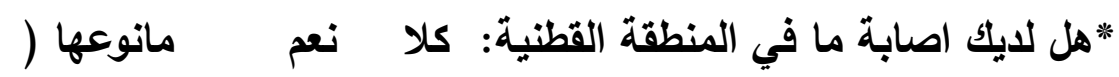

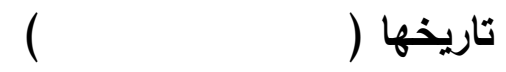

*"هل مدة دوام الالم في الركبتين: طويلة متقطعة مع الجهد والعمل

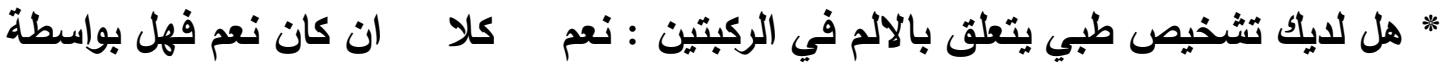

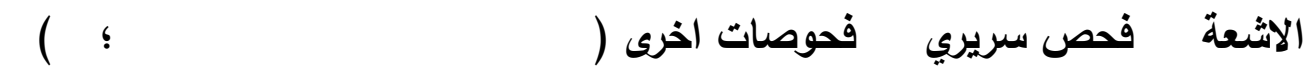

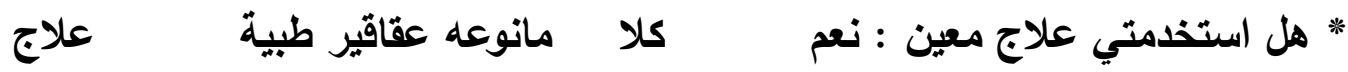

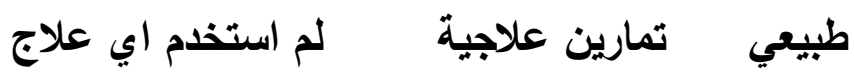
"ملاحظات اخرى تذكر

$r$ r. 